\title{
MALTRAVIESO. EL SANTUARIO EXTREMEÑO DE LAS MANOS
}

\author{
MALTRAVIESO. A HANDS SANCTUARY \\ IN EXTREMADURA
}

SERGIO RIPOLL LÓPEZ (*)

EDUARDO RIPOLL PERELLÓ $(*)$

HIPÓLITO COLLADO GIRALDO $(* *)$

MARTÍ MAS CORNELLÁ $(*)$

JESÚS F. JORDÁ PARDO $(*)$

LABORATORIO DE ESTUDIOS PALEOLÍTICOS

\author{
$(*)$
}

\begin{abstract}
RESUMEN
El proyecto de investigación llevado a cabo en la cueva de Maltravieso, no sólo ha supuesto un notable incremento en el inventario de representaciones artísticas -manos, zoomorfos e ideomorfos- conocidos en la cueva de Maltravieso, sino que aporta importantes novedades, respecto al momento cronológico de realización de las distintas manifestaciones, fases de ejecución, técnica empleada en la elaboración de las figuras y tipología de los motivos. Otra novedad importante derivada de nuestra investigación, ha sido la constatación de la inexistencia de mutilaciones en las manos. Estas amputaciones, tan largamente comentadas por la bibliografía tradicional, no son tales, sino simples ocultaciones intencionales del dedo meñique con el mismo pigmento empleado para plasmar la mano en negativo.
\end{abstract}

\footnotetext{
ABSTRACT

The project of investigation carried out in the cave of Maltravieso has not only yielded a notable increase in the inventory of artistic depictions -hands, zoomorphs and

(*) Dpto. de Prehistoria e Historia Antigua de la Universidad Nacional de Educación a Distancia. Avda. Senda del Rey, 7 , 28040 Madrid.

(**) Dirección General de Patrimonio Cultural. Consejería de Cultura y Patrimonio. Junta de Extremadura. Almendralejo, 4, 06800 Mérida. Badajoz.

(***) A este Laboratorio pertenecen los becarios J.A. Martos, F.J. Muñoz, J.R. López, M. Muñiz S. Rubio, J. Panera y J. Herranz.

El artículo fue remitido en su versión final el 12-VII-99.
}

ideomorphs-that are known in the cave, but has also produced some new information with regard to the chronological framework of the production of the various depictio$n s$, their phases of execution, the techniques used in creating the figures, and the typology of the motifs. Another important contribution of our work has been the observation that mutilations of these hands do not exist. The supposed amputations, which have been commented on widely in the traditional literature, are nothing of the kind -they are simply an obscuring of the little finger, with the same pigment as was used to make the hand stencil.

Palabras clave: Arte rupestre Paleolítico. Manos. Grabados.Auriñaciense. Gravetiense. Solutrense. Nuevas tecnologías.

Keywords: Palaeolithic rock art. Hands. Engravings. Aurignacian. Gravettian. Solutrean. New technologies.

\section{INTRODUCCIÓN}

Hasta donde ha llegado el hombre en su ocupación de las tierras habitables del ecúmene ha sido portador de la representación de la mano como un símbolo de su propio ser. Uno de los puntos extremos de las migraciones humanas es la América austral: allí se encuentran los espléndidos frisos de manos negativas, junto con otras pinturas, de la gran garganta del Río Pinturas (Argentina). De Maltravieso a la Patagonia hay una larga distancia, que se acrece si se recuerda que el hombre entró en el con- 
tinente americano por el estrecho de Behring. Además, larga también es la dimensión temporal: 30000/25000 BP para Maltravieso -o Gargas, La Fuente de El Salín. El Castillo, etc.- y 5.000/3.000 a.C. para Río Pinturas.

Enfrentarse con el estudio de una cueva como Maltravieso será siempre un reto a pesar de la ayuda de las tecnologías actuales, que aquí hemos utilizado ampliamente. De ellas no disponían los pioneros de las estudios de arte prehistórico y, entre ellos, Carlos Callejo Serrano que supo valorar enseguida su propio y muy notable descubrimiento y cuyos pasos hemos seguido.

En una visita realizada en 1994 por técnicos de la Dirección General de Patrimonio, se constató el grado de abandono y deterioro, no sólo del yacimiento, sino también de su entorno, que en caso de no atajarse con prontitud abocaría irremisiblemente a la pérdida de todas las representaciones artísticas. En el informe emitido tras la visita se daba cuenta de que el estado de conservación era el resultado de un largo proceso que comienza ya con el mismo descubrimiento de la cueva, pero que se aceleró fundamentalmente a partir de la segunda mitad de la década de los sesenta con la construcción indiscriminada de edificaciones en las proximidades, que originaron en 1968 algunos derrumbes parciales en el interior de la cueva con riesgo de pérdida de cuatro paneles con pinturas. A mediados de los años ochenta coincidiendo con las intenciones de la Diputación Provincial de Cáceres de acondicionar el entorno de la cueva, se llevaron a cabo los trabajos de documentación efectuados por el profesor $\mathrm{F}$. Jordá y don J.L. Sanchidrián que elaboraron un proyecto detallado que finalmente no se llevó a cabo y las constantes acciones vandálicas de que fueron objeto, volvieron a sumir a Maltravieso en el más absoluto de los abandonos.

Ante esta lamentable situación la Dirección General de Patrimonio, decidió la recuperación integral no sólo de la cueva, sino también del espacio que la rodea. Siguiendo las directrices marcadas por los técnicos del Servicio de Patrimonio Histórico Artístico, se coordinó un proyecto multidisciplinar con el objetivo de recuperar de forma definitiva el yacimiento y ponerlo en valor mediante la creación de un Centro de Interpretación que pusiera a disposición del público en general el contenido histórico y artístico de la cueva de Maltravieso.

Entre los meses de octubre y noviembre del año 1996 se procedió a la documentación arqueológica de la cueva, que fue asumida por el Laboratorio de
Estudios Paleolíticos de la U.N.E.D., estando codirigido por los autores de este texto.

La revisión cuidadosa de la totalidad de la cueva y la aplicación de nuevos sistemas de documentación basados en el empleo de longitudes de onda fuera del espectro luminoso visible generó un importante número de representaciones inéditas lo que obligó a un replanteamiento de nuestro proyecto inicial que pasó, en primer lugar, por un cambio en la tradicional numeración de los paneles de cara a mejorar nuestra operatividad y con objeto de clärificar su lectura en futuras publicaciones. Para todo el proceso de toma de datos se empleó un sistema no destructivo basado en la aplicación de una serie de fichas de catalogación a la que se adjuntaba una serie completa de fotografías, además de la correspondiente filmación en vídeo. Este material gráfico fue empleado a posteriori, tras su digitalización, para la obtención de las reproducciones-calcos correspondientes a cada motivo.

La consecución de esta investigación no sólo ha supuesto un notable incremento en el inventario de representaciones artísticas conocidas en la cueva de Maltravieso, sino que aporta importantes novedades, algunas de ellas ya intuidas brevemente con anterioridad, respecto al momento cronológico de realización de las manifestaciones, fases de ejecución, técnica empleada en la elaboración de las figuras y tipología de los motivos.

\section{BREVES NOTAS HISTORIOGRÁFICAS}

La primera de las manos representadas en el arte paleolítico que se conoció fue hallada por Émile Cartailhac y el abate Henri Breuil en su expedición a la cueva deAltamira en 1902 (Breuil y Cartailhac, 1906). En los años 1905/1906 F. Regnault empezó a explorar la cueva pirenaica de Gargas (HautesPyrénées), encontrando algunas de sus manos pintadas, estudio que fue asumido posteriormente por Cartailhac y Breuil. Con los años se sucedieron otros descubrimientos de manos, pero siempre en lo que entonces se denominaba "provincia francocantábrica". pero la geografía del arte paleolítico de la Península Ibérica sufrió cincuenta años más tarde, en 1956, un cambio sustancial al anunciarse el de las manos pintadas de Maltravieso, siendo el autor de tan importante hallazgo científico el erudito y arqueólogo C. Callejo Serrano.

La cavidad había sido encontrada en 1951 al avanzar la explotación de una cantera de la que se

T. P., 56, n. ${ }^{\circ} 2,1999$ 


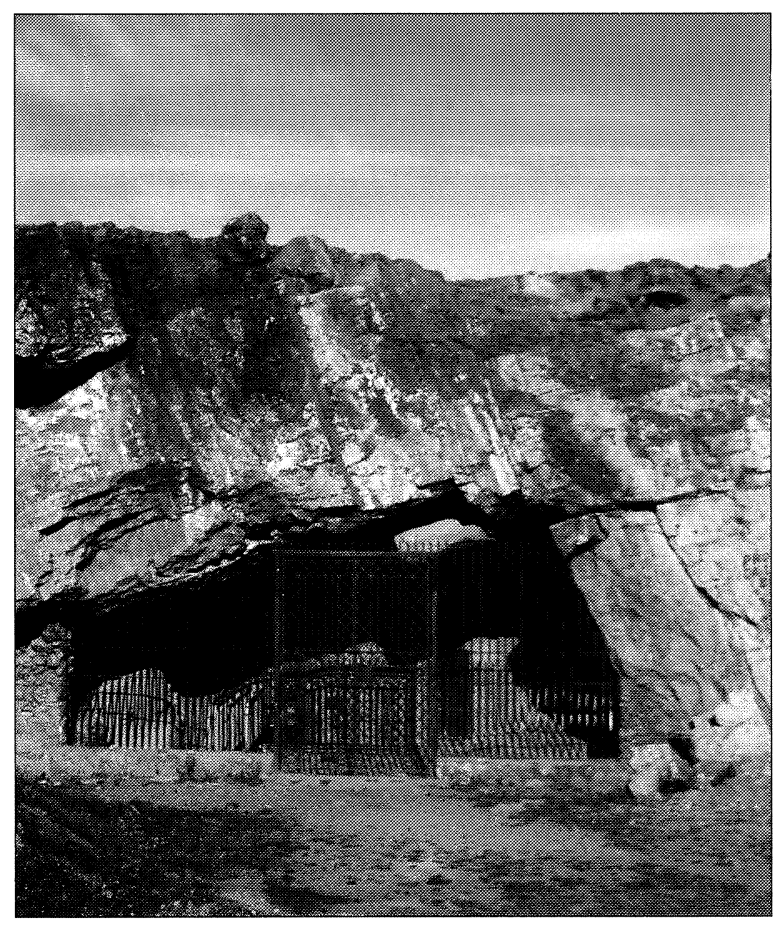

Lám. I. Vista de la actual boca de la Cueva de Maltravieso, antes de que se construyeran los edificios que hoy se sitúan en sus cercanías.

extraía caliza para transformarla en cal (Lám. I). Entonces se localizaron algunos materiales arqueológicos, de los que se hizo eco la prensa extremeña. En aquella primera e irregular recolección, se retiraron algunos restos humanos, cerámicos y paleontológicos por varias personas, quedando dichos materiales dispersos.

En 1955, C. Callejo inició la recuperación y el estudio de aquellos materiales, empezando al mismo tiempo la exploración sistemática de la cueva. En 1956, tuvo la fortuna de identificar una parte de las manos que conserva la caverna. Esta habría quedado como un hito más en la rica carta arqueológica cacereña de no ser por el alto valor de su hallazgo en una zona carente de este tipo de representaciones.

C. Callejo hizo llegar su estudio a algunos arqueólogos y a diversas instituciones. Así llego a las manos del profesor M. Almagro Basch, que visitó la cueva en 1959 y en 1960, esta vez con el profesor F. Jordá Cerdá, siempre acompañados por el descubridor. Ambos especialistas refrendaron el carácter paleolítico de las representaciones en ese momento atribuyéndolas al Perigordiense o al Auriñaciense medio (Almagro Basch, 1969) (Lám. II).
M.Almagro Basch comunicó la noticia del descubrimiento al abate $\mathrm{H}$. Breuil que, a su vez, publicó en una nota titulada "Découverte d'une grotte ornée paléolithique dans la province de Cáceres (Nord-ouest [sic] de l'Espagne)" (1960).

Con la misma fecha de 1960, M. Almagro Basch publicó su propio estudio. Unos años después lo amplió y puso al día en una "guía" publicada por la Dirección General de Bellas Artes con la colaboración del Ayuntamiento de Cáceres. Los datos esenciales sobre la cueva y su contenido artístico eran prácticamente los que había publicado C. Callejo, pero ahora con más detalle y añadiendo entre los hallazgos arqueológicos una punta de lanza del Bronce final y algunas otras manos al repertorio pictórico. En total, M. Almagro documenta treinta manos, numerosas series de puntuaciones, tres trianguliformes, un serpentiforme, varias curvas concéntricas, líneas verticales paralelas y una posible cabeza de cérvido (Almagro Basch, 1969).

En el mes de marzo de 1969 tuvieron lugar en Mérida las sesiones del $\mathrm{XI}^{\circ}$ CongresoArqueológico Nacional que se clausuró en Cáceres. Al Congreso se presentaron dos comunicaciones referidas a Maltravieso (Callejo Serrano, 1970; Jordá Cerdá, 1970).

Durante la celebración de esta reunión, C. Callejo propuso a E. Ripoll Perelló efectuar una visita a la cueva, durante la cual se produjo el descubrimiento en la Sala de las Chimeneas de un conjunto de líneas grabadas entre las que identificó un protomos de cierva y otro zoomorfo acéfalo.

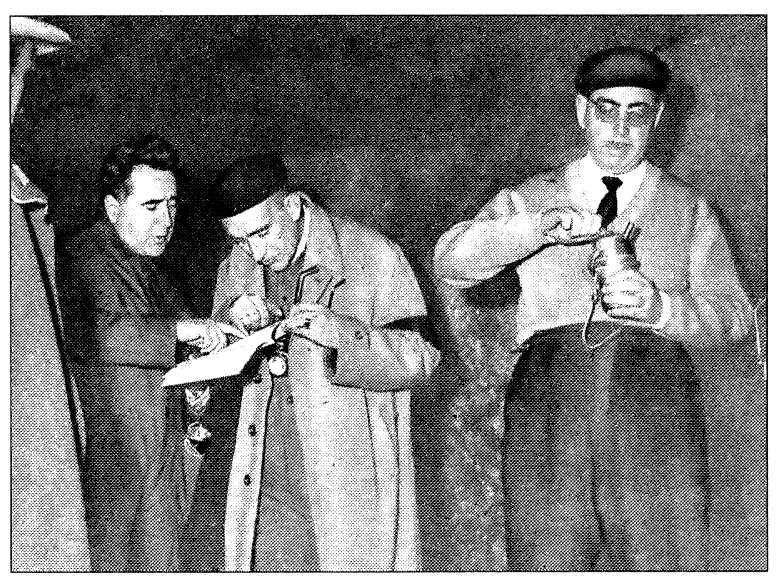

Lám. II. De izquierda a derecha, Martín Almagro, Carlos Callejo y Francisco Jordá (1960) se disponen a iniciar una de las exploraciones llevadas a cabo en la Cueva de Maltravieso (Cortesía archivo F. Jordá). 
La labor de F. Jordá Cerdá y J.L. Sanchidrián, estaba enmarcada en el proyecto de investigación denominado "El Pleistoceno en Extremadura", dentro del cual se efectuaron la documentación e inventario de las manifestaciones artísticas de la cueva cacereña. Entonces se registraron 37 siluetas de manos, 7 de ellas inéditas (Sanchidrian Torti, 1988/1989; Jordá Cerdá y Sanchidrian Torti, 1992).

Señalaron, así mismo, que a su parecer, posiblemente, los dedos meñiques no representados, no estuvieran ni mutilados ni doblados, sino que pudieran en algún caso haber sido repintados una vez realizada la silueta. En cuanto a la atribución cultural del conjunto, establecieron que la asociación entre trianguliformes, manos y serpentiformes correspondía a un Magdaleniense medio, en torno al 14000.

La última actuación efectuada en la cueva de Maltravieso ha sido la realizada por los autores de este artículo, con el objetivo de documentar definitivamente el yacimiento de cara a la construcción del Centro de Interpretación-Museo de la Cueva de Maltravieso.

Este proyecto se ha desarrollado paralelamente a los trabajos del I.C.R.B.C (Instituto de Conservación y Restauración de Bienes Culturales) y el Ayuntamiento de Cáceres. El objetivo del trabajo conjunto era recuperar la Cueva de Maltravieso, que había sufrido un alto grado de contaminación debido tanto a su posición geográfica, dentro de la ciudad de Cáceres, como al hecho de haber sido objeto de numerosos actos vandálicos que deterioraron y pusieron en peligro las representaciones pictóricas que contiene. A partir de estos estudios se ha colaborado en la realización de un Museo-Centro de Interpretación del yacimiento, en el que el público pueda disfrutar de la cavidad sin que entrañe ningún riesgo directo para su conservación.

Nuestros trabajos han servido para complementar este importante proyecto de protección y restauración documentando el arte rupestre de forma definitiva sobre un soporte informático que permita su consulta directa, evitando así continuadas visitas al yacimiento con los riesgos de contaminación que esto conlleva y al propio tiempo dar a conocer la cavidad a los diferentes especialistas interesados en el tema.

A partir de un análisis exhaustivo de todas las superficies de la cueva susceptibles de contener representaciones artísticas, hemos localizado una total de 71 representaciones de manos y huellas leves de las que un día lo fueron.

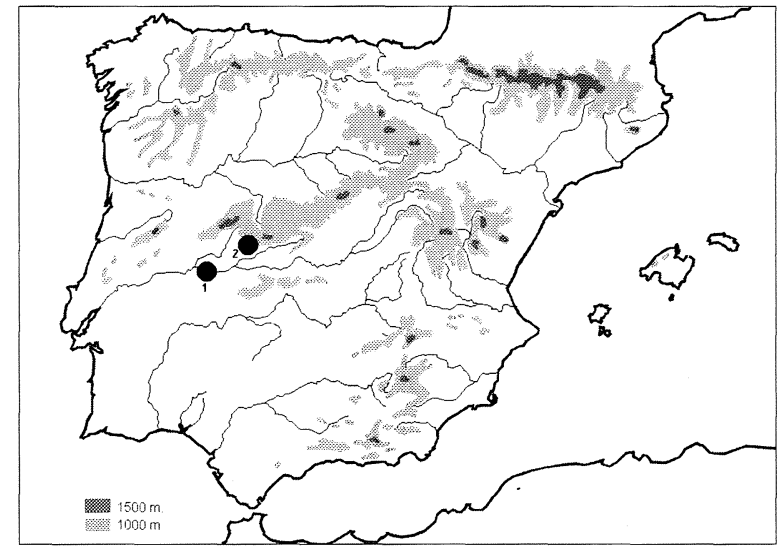

Fig. 1. Localización geográfica de las cuevas de Maltravieso y de La Mina de Ibor.

Con nuestro trabajo hemos querido redescubrir el yacimiento de Maltravieso en función de los adelantos y nuevos hallazgos acaecidos tanto en la Península Ibérica como en Extremadura, dentro del contexto delArte Rupestre Extracantábrico, dándole la valoración merecida en el ámbito científico nacional e internacional y recuperándolo a nivel divulgativo.

\section{CARACTERÍSTICAS GEOLÓGICAS DE LA CUEVA DE MALTRAVIESO}

La Cueva de Maltravieso se encuentra situada en la zona Sur de la ciudad de Cáceres (Fig. 1). Su entrada se abre en el frente de una antigua cantera utilizada para la extracción de las calizas paleozoicas en las que se desarrolla la cavidad, cantera que en la actualidad ha sido transformada en un parque urbano. Esta zona calcárea es conocida en Cáceres con el nombre de El Calerizo y durante mucho tiempo constituyó una de las áreas urbanas más deprimidas económicamente de la ciudad, precisamente por los problemas geotécnicos que plantean las características del subsuelo de cara a la construcción, a los que hay que unir los debidos a las antiguas explotaciones mineras abandonadas de fosfatos y calizas llevadas a cabo en esta formación carbonatada desde tiempos históricos (I.G.M.E., 1985)

En la primera publicación científica sobre la cueva (Callejo Serrano, 1958) ya aparecen las primeras notas sobre sus características geológicas escritas con gran acierto por el profesor Dr. F. Hernández Pacheco, quien en 1951 realizó su pri-

T. P., 56, n. ${ }^{\circ} 2,1999$ 
mera visita a esta cavidad cacereña (Jordá Pardo, 1992).

Desde el punto de vista geológico, la Cueva de Maltravieso se encuentra ubicada en el extremo centro-meridional del occidente de la zona CentroIbérica del Macizo Ibérico o Macizo Hespérico (Julivert et alii, 1972; Julivert, 1983). En general, puede decirse que esta zona del Macizo Ibérico no es especialmente rica en afloramientos calcáreos (Val y Hernández, 1989), correspondiendo estos a escasas excepciones de intercalaciones carbonatadas en el registro estratigráfico de la zona Centro-Ibérica, con un mayor o menor grado de recristalización y dolomitización, situadas, dentro de la escala cronoestratigráfica, en el Precámbrico, el Cámbrico, el Devónico y el Carbonífero.

El aparato kárstico de la Cueva de Maltravieso se desarrolla en una estrecha franja de calizas y dolomías marmóreas del Carbonífero inferior (Paleozoico) (Tena Dávila y Corretgé, 1982), que en la zona que nos ocupa se encuentran plegadas y fracturadas, dispuestas en bancos de 1 a $2 \mathrm{~m}$, formando parte del flanco suroriental del sinclinal de Cáceres, estructura de plegamiento originada por la orogenia Varisca, cuyo núcleo se encuentra constituido por pizarras también carboníferas, siguiendo su eje la dirección Noroeste-Sureste. Las calizas se encuentran limitadas en los bordes del sinclinal por materiales impermeables o de baja permeabilidad, como pizarras, areniscas y cuarcitas. Estas calizas, masivas, de color gris, con óxidos de hiero y abundantes arcillas en los planos de estratificación, se encuentran además afectadas por una fracturación varisca que da lugar a un sistema de diaclasas, fracturación que se manifiesta con más claridad que la superficie de estratificación $\left(\mathrm{S}_{0}\right)$. Este sistema de superficies de debilidad, estratificación y fracturación, es el responsable de las directrices generales de la karstificación externa y del acavernamiento.

Geomorfológicamente, la Cueva de Maltravieso se encuentra situada en la unidad morfoestructural de la Península Ibérica denominada Macizo Hespérico Meridional (Gutiérrez Elorza, 1994) y más concretamente, en la parte central de la llamada penillanura extremeña, comprendida entre la Depresión del Tajo al Norte y la Depresión del Guadiana al Sur. El marco cronológico de la penillanura extremeña es muy amplio encontrándose acotado por los arrasamientos premesozoicos del Macizo Hespérico y el desarrollo plio-cuaternario de las rañas (Rodríguez Vidal y Díaz del Olmo, 1994).

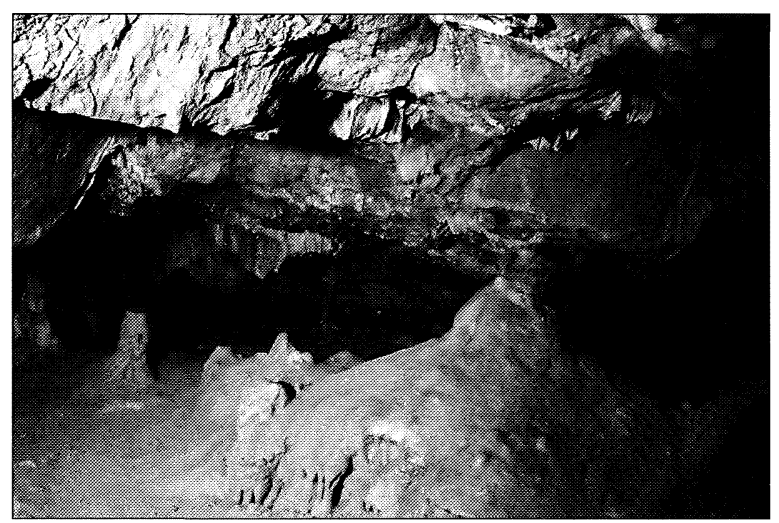

Lám. III. Panorámica general del conjunto Sala de las Columnas visto desde la entrada de la cueva.

\section{DESCRIPCIÓN DE LA CAVIDAD}

La actual entrada o boca de acceso a la cueva se abre en la pared frontal de la antigua cantera antes mencionada, resultando de esta forma una abertura triangular, correspondiente a las sección de la galería por la que se accede a la cueva. Esta galería fue cortada por la cantera y su continuación hacia el interior de la cavidad se destruyó a consecuencia de las actividades mineras, quedando en la actualidad el sector de cavidad más próximo a la primitiva entrada, situado en la última sala.

En general, los conductos, galerías y salas que configuran la cueva presentan un condicionamiento estructural muy acusado, como así se desprende del análisis de las direcciones de los segmentos longitudinales del trazado subterráneo (Val y Hernández, 1989). Por tanto, la cueva de Maltravieso corresponde a un karst estructural, originado fundamentalmente por corrosión desarrollada a favor de los planos de debilidad de la roca carbonatada, con una alimentación autóctona, producida por infiltración de agua de lluvia de forma gravitacional. En la actualidad constituye un ejemplo de karst muerto, en el que los procesos de reconstrucción litoquímica son mínimos, manifestándose en algunos puntos procesos de alteración de cierta importancia en las formaciones y paredes de la cueva. Los conductos que componen la cavidad se encuentran parcialmente colmatados por sedimentos detríticos, tanto autóctonos como alóctonos, sobre los cuales se han desarrollado en algunos puntos espeleotemas (Lám. III). 


\section{LA RECUPERACIÓN DE UN PARAJE KÁRSTICO URBANO}

Con la rehabilitación sufrida por este paraje kárstico realizada a partir de 1986, el entorno de la Cueva de Maltravieso ha adquirido, dentro de sus especiales circunstancias, unas características de visitabilidad y conservación muy dignas, que permiten el disfrute de la zona, así como la conservación y perdurabilidad en el tiempo de las singulares manifestaciones artísticas prehistóricas que la cueva contiene. Estas sustanciales mejoras hacen que una de las escasa cavidades kársticas urbanas españolas se encuentre plenamente integrada en el entorno de la ciudad.

En este sentido, es necesario destacar el hecho de que, dada la escasez de zonas kársticas y cavidades en esta zona del Macizo Hespérico, la Cueva de Maltravieso constituye por si misma, independientemente de servir de soporte de manifestaciones artísticas prehistóricas de indiscutible valor cultural, un interesante georrecurso cultural no renovable o punto de interés geológico, que integra el $\mathrm{Pa}$ trimonio Geológico de Extremadura.

La situación de la Cueva de Maltravieso dentro del casco urbano, si bien ha constituido en el pasado uno de los factores de su degradación y de la desaparición de parte de su recorrido, en la actualidad ofrece las mejores oportunidades para la adecuada promoción de este georrecurso cultural, dado que su integración en un parque público y su cercanía a centros de enseñanza permiten la explicación sobre el terreno de los aspectos de la geomorfología kárstica, los cuales son difíciles de observar por los estudiantes y el público en general en esta zona de la península.

\section{TEMÁTICA DE LAS DISTINTAS REPRESENTACIONES}

En el conjunto de las manifestaciones artísticas de Maltravieso se constata la utilización de la pintura y del grabado. En la pintura encontramos el uso de diferentes pigmentos, fundamentalmente rojos (posiblemente obtenidos del propio sedimento de la cueva) y en menor medida marrones, negros y blancos, con los que se han realizado manos, ideomorfos y zoomorfos.

El tema básico en esta estación son las representaciones de manos, que se encuentran en 20 de los 29 paneles diferenciados. Junto a las manos y en menor proporción, aunque con una importancia significativa puesto que muchas de las figuraciones no habían sido documentadas, se representan signos (puntuaciones y líneas paralelas, siempre en pintura), figuraciones zoomorfas y trianguliformes grabados o pintados, que aparecen en los diferentes paneles unas veces de manera independiente y otras asociada a aquéllas (Fig. 2).

\section{LAS MANOS}

Las improntas de manos son el tema básico de las representaciones documentadas en Maltravieso. El conjunto está formado por 71 siluetas distribuidas heterogéneamente a lo largo de la cueva.

Hasta el inicio de nuestros estudios el corpus de manos era de 37. Durante nuestra investigación hemos identificado estas representaciones, incluyendo la recuperación de una descubierta por $\mathrm{M}$. Almagro (1960) y no mencionada en posteriores trabajos (Jordá Cerdá y Sanchidrián Torti, 1992; Sanchidrián Torti, 1988/1989), y hemos registrado otras 44 nuevas.

En la tabla 1 podemos apreciar la evolución seguida en la identificación de representaciones de manos a lo largo de la historia de la investigación de Maltravieso. La información aparece estructurada por salas y dentro de éstas por paneles. Si a lo largo de la historia de la investigación se ha mantenido el nombre de las salas, no ha sucedido así con los paneles, ya que cada investigador les dio distinta numeración. En la citada figura podemos apreciar la equivalencia de la diferente numeración de los paneles y las representaciones de manos que cada autor registró en su estudio.

\section{Realización de las representaciones de manos}

Todas las improntas de manos fueron realizadas con ocre rojo que han adquirido diversas tonalidades, aunque inicialmente debió de ser la misma, y en tres de ellas se emplearon además pigmentos blancos, como veremos más adelante. Aunque todavía no se ha realizado un análisis exhaustivo de la procedencia de estos materiales, el ocre rojo y los pigmentos negros se obtuvieron probablemente de las arcillas que hay depositadas en la cueva.

A excepción de tres representaciones, todas las improntas de mano han sido realizadas en negativo. Nuestra investigación nos induce a pensar que es-

T. P., 56, n. ${ }^{\circ} 2,1999$ 


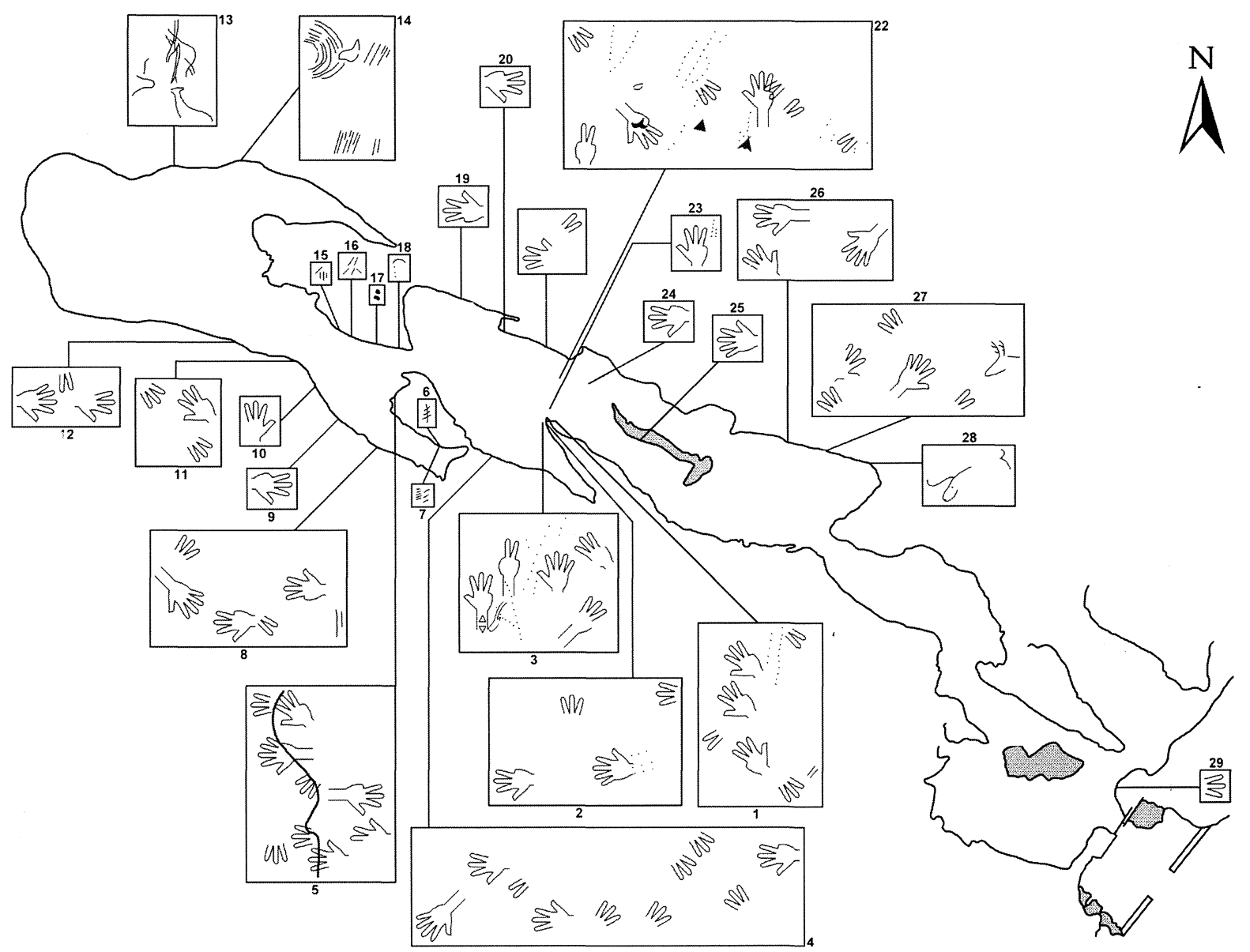

Fig. 2. Esquema de distribución de los veintinueve paneles a lo largo de la estación.

tas improntas se elaboraron apoyando la mano, bien la palma o el dorso, sobre la superficie y posteriormente se aplicó el pigmento mediante soplado, creando de esta forma el negativo, aunque no descartamos el empleo de otras técnicas.

En la Sala de las Pinturas, en el panel III denominado "Camarín de las Manos" (Almagro Basch, 1960), se localizan tres representaciones realizadas mediante técnica mixta en la aplicación del pigmento (Lám. IV). Por un lado se trata de manos de color blanco en positivo, que a su vez lo son en negativo puesto que poseen un halo de color rojo. Realizamos un minucioso examen utilizando una potente lupa, que nos permitiera determinar si la parte interior de las manos era la superficie de la colada calcítica blancuzca, o si bien se trataba de un pigmento. De este modo comprobamos que la superficie original es de color grisáceo, mientras que el interior de las manos es de color blanquecino marfileño. En su realización probablemente se aplicaron pigmentos blancos en la palma, posterior- mente ésta se apoyó en la roca soporte y se proyectó el colorante ocre rojo mediante soplado, depositándose alrededor de la palma y entre los dedos, definiendo una mano en negativo con una silueta muy

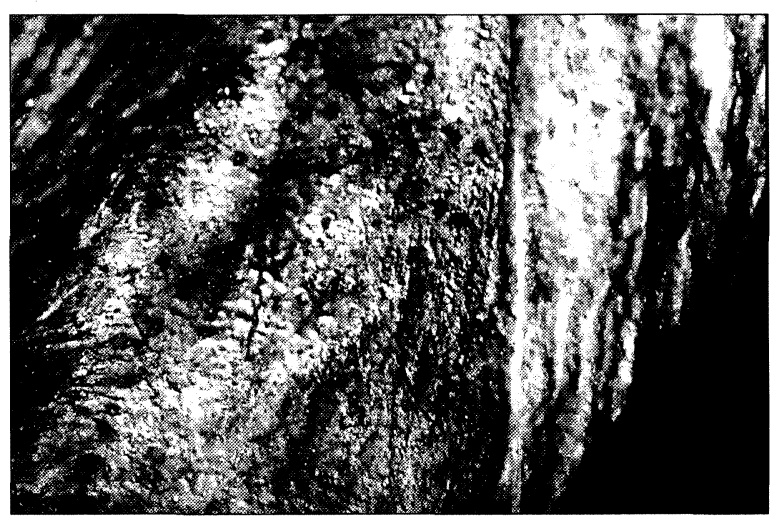

Lám. IV. Fotografía con película infrarroja del Camarín de las Manos (panel III). Esta técnica nos permite observar el orden de superposición de las distintas representaciones ya sean incisas o pintadas. 


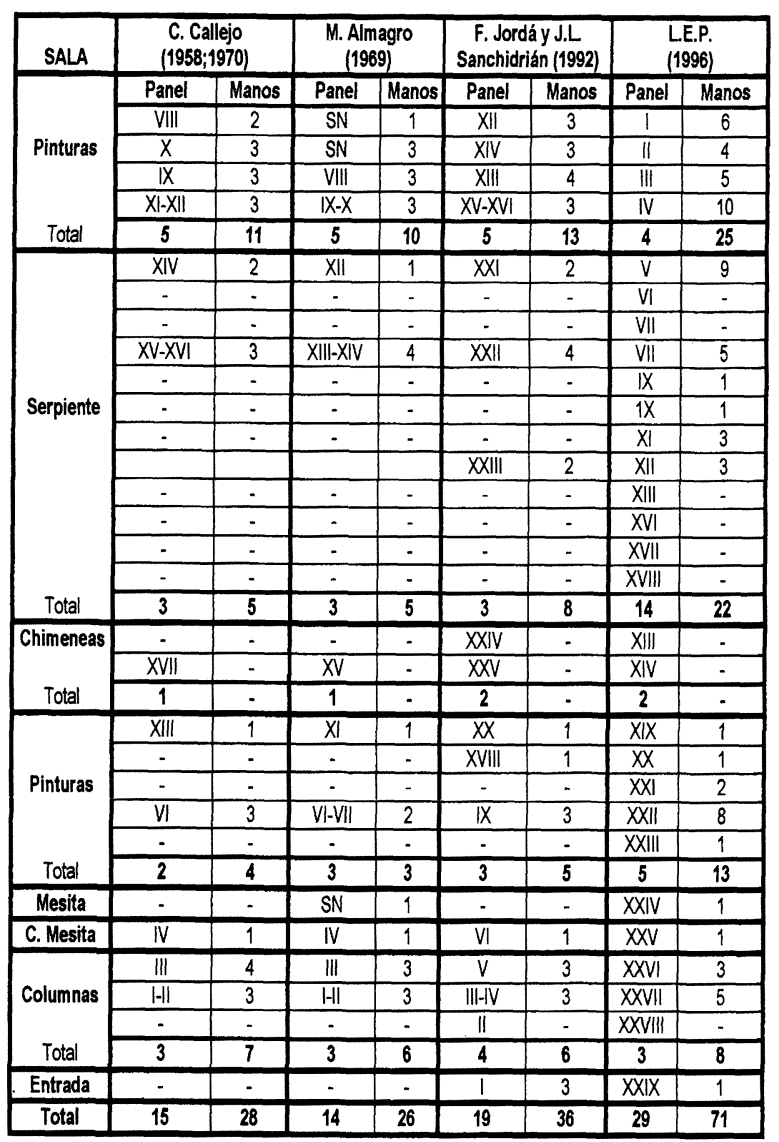

Tab. 1. Representaciones de manos documentadas en los distintos momentos de investigación de Maltravieso. (L.E.P. = Laboratorio de Estudios Paleolíticos; $\mathrm{SN}=\mathrm{Sin}$ Numeración).

clara. Las manos: 7, 8 y 9 del panel III son los únicos casos existentes en los que se aprecia esta técnica. Por otro lado este panel es uno de los más significativos de la cueva dada la asociación de temas que contiene.

\section{Distribución de las representaciones de manos}

Encontramos representaciones de manos en todas las salas, con excepción de la Sala de las Chimeneas que fue la entrada original de la cueva. $\mathrm{La}$ mayor concentración aparece en la zona central, con la Sala de las Pinturas, que reúne en 9 paneles 38 representaciones de manos (el $55 \%$ ), y la Galería de la Serpiente con $22(31 \%)$. Estos resultados contrastan con las representaciones localizadas en la Entrada, Galería y Sala de la Mesita todas ellas con tan sólo una representación (Fig. 3).

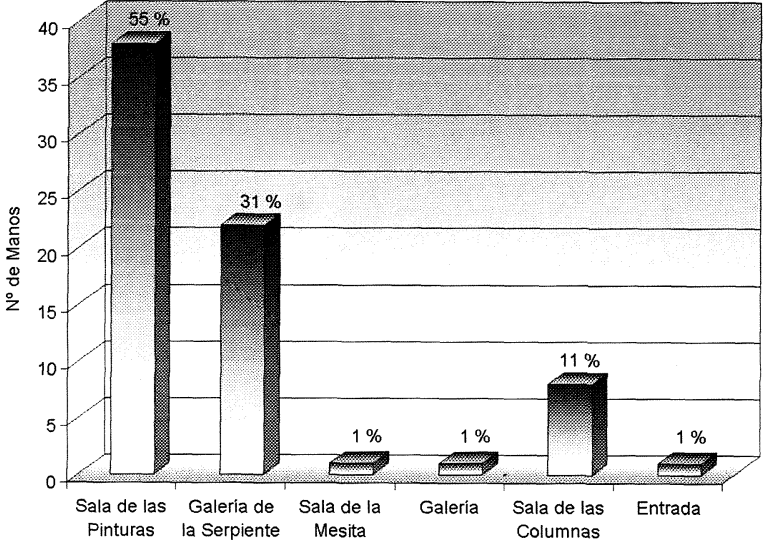

Fig. 3. Gráfico con la distribución porcentual de las representaciones de manos en las diferentes salas

Las manos se localizan en 20 de los paneles diferenciados en Maltravieso.

'En función del número de representaciones de manos, podemos diferenciar entre (Fig. 4A):

- Paneles que sólo contienen una mano: IX, X, XIX, XX y XXIV.

- Paneles que contienen una mano y algún otro tipo de representación: XXIII, XXV y XXIX.

- Paneles que contienen más de una mano: IV, VIII, XI, XII, XXI, XXVI.

- Paneles que contienen más de una mano y algún otro tipo de representación: I, II, III, V, XXII y XXVII.

$\mathrm{Al}$ ser el recorrido de la cueva de Maltravieso casi rectilíneo, es sencillo diferenciar entre parte inicial, media o final. De este modo consideramos la Sala de las Chimeneas como parte inicial, teniendo en cuenta que fue posiblemente la entrada originaria, la Galería de la Serpiente, Sala de las Pinturas, Sala de la Mesita, Galería y Sala de las Columnas como parte media de la cueva y la Sala de la Entrada corresponde como parte final.

En otras cuevas con representaciones de manos, éstas aparecen interrelacionadas con grandes conjuntos artísticos. Únicamente en Maltravieso y en Gargas hallamos manos aisladas o asociadas entre ellas sin relación con zoomorfos o ideomorfos. Para Leroi-Gourhan (1964) las figuras de manos se disponen espacialmente en dos zonas concretas de las cuevas: en áreas próximas a la entrada o en zonas medias, siendo raras las que se encuentran al final del cavernamiento.

En Maltravieso las manos se distribuyen exclusivamente en el área media de la cueva, donde se hallan 70 representaciones, el $99 \%$, mientras que 


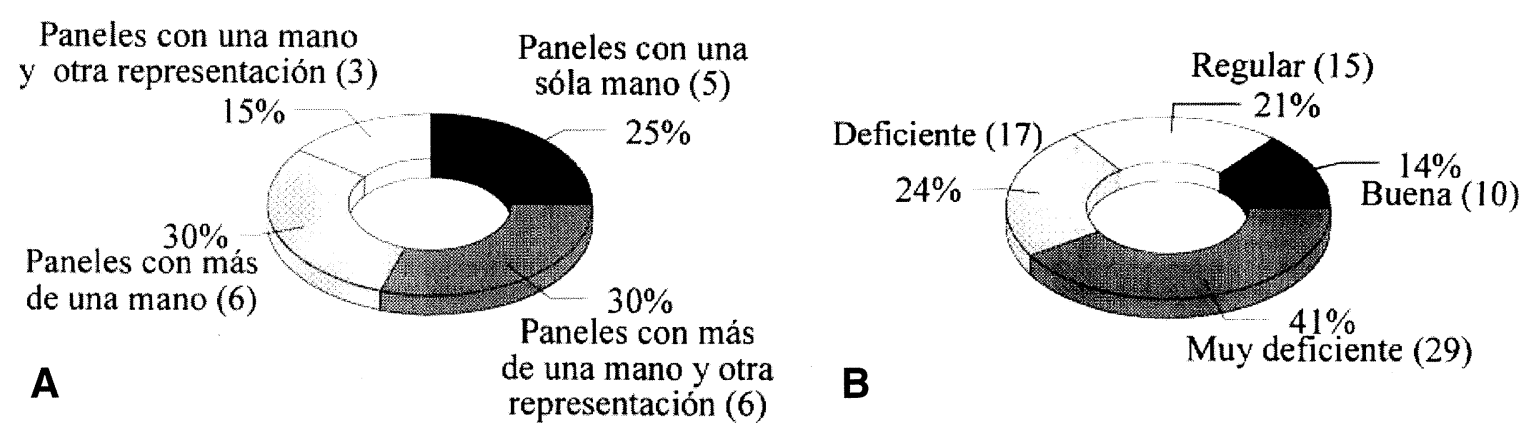

Fig. 4. A. Distribución de los paneles en función de las representaciones que contienen. B. Estado de conservación de las manos.

al final de la cavidad solo se documenta $1 \mathrm{y}$ al inicio ninguna, donde sí se encuentran zoomorfos e ideomorfos.

\section{Anatomía y orientación}

Respecto a la anatomía de las representaciones de manos de Maltravieso, en el mejor de los casos, se puede diferenciar entre: antebrazo, palma y dedos. En función de su presencia o ausencia y su orientación podremos inferir ciertos aspectos relativos a su realización y en algunos casos a su interpretación.

El primer elemento que debemos tener en cuenta es el estado de conservación de las representaciones, puesto que va a condicionar la observación de las distintas partes de las manos y por tanto será un aspecto de extraordinaria importancia para el planteamiento de hipótesis en su interpretación. Con la finalidad de ser lo más objetivos posible hemos diferenciado cuatro categorías (Fig. 4B y Tab. 2)

- Grado de conservación bueno.Aquellas representaciones que han sido documentadas a simple vista, y en las que podemos apreciar el contorno perfectamente delimitado de los dedos, la palma, y de la muñeca y antebrazo si los tuviera. Solamente 10 manos, es decir el 14\%, muestran buena conservación.

- Grado de conservación regular. En este campo incluimos las representaciones de manos que han perdido parte del pigmento con que fueron realizadas, y los contornos de dedos y manos no se observan tan nítidamente como en el caso anterior. En total 15 manos, el $21 \%$, todas provistas de palma excepto 6.

- Grado de conservación deficiente. Las representaciones con los contornos desvaídos que difi- cultan su visualización. Casi una cuarta parte de las manos, 17, se adscriben a esta categoría. Pese a su estado de conservación, en nueve casos es apreciable la palma, en dos además la muñeca y el antebrazo y en uno la muñeca, mientras en los nueve restantes sólo los dedos.

- Grado dé conservación muy deficiente. Incluye las representaciones de manos cuya observación de los contornos de dedos y palmas es tan compleja que fue necesario un análisis exhaustivo en el laboratorio mediante el uso de técnicas específicas como diapositivas, vídeo o tratamiento digital de las imágenes. Este estudió se completó en posteriores visitas a la cavidad en momentos en que las condiciones de humedad aumentaron, facilitando así su observación. Es la categoría en la que más manos se adscriben, el 41 \% (29). La palma es apreciable sólo en tres representaciones, sin muñeca o antebrazo, y en las veintiséis restantes sólo los dedos.

Casi en el $60 \%$ de las manos (41) sólo son visibles sus dedos, siendo su palma total o parcialmente inapreciable (Tab. 2). Probablemente este hecho sea debido al estado de conservación, si consideramos que en veintiséis casos es deficiente, en nueve muy deficiente y en seis regular. Pese a estos datos en tres manos se distinguen los cinco dedos, en siete, cuatro, en veintiuna, tres, y en diez sólo dos.

En el $40 \%$ de las representaciones se distingue la palma (30), de las que diez van acompañadas de la muñeca y siete además del antebrazo, a pesar de que la conservación sea deficiente en tres casos y muy deficiente en ocho (Fig. 4A). En más de la mitad, 16 , son perceptibles cuatro dedos, estando todos representados sólo en nueve improntas, mientras que tres solo muestran tres dedos, y las dos restantes dos dedos (Fig. 5).

Respecto a qué dedos se representaron en primer lugar debemos tener en cuenta que en 33 represen- 


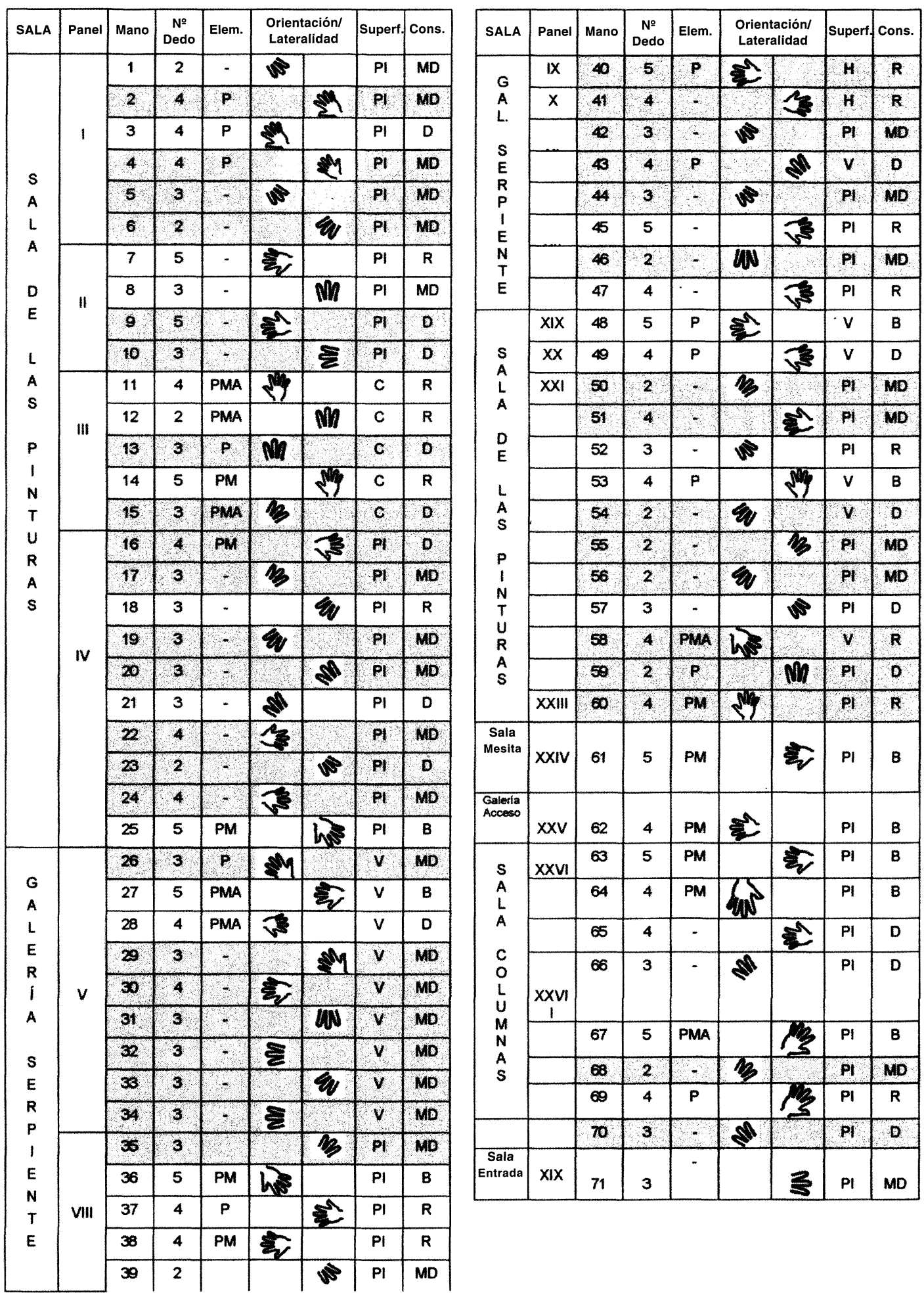

Tab. 2. Cuadro-resumen de las características básicas de las representaciones de manos. En sombreado figuran las nuevas representaciones halladas durante nuestros trabajos en la cavidad (Elementos: $\mathrm{P}=$ palma; $\mathrm{M}=$ muñeca; $\mathrm{A}=$ antebrazo; Superficie: $\mathrm{PI}=$ pared inclinada; $\mathrm{C}=$ cóncava; $\mathrm{V}=$ vertical; $\mathrm{H}=$ horizontal; Conservación: $B=$ buena; $R=$ regular; $\mathrm{D}=$ deficiente; $M D=$ muy deficiente). 

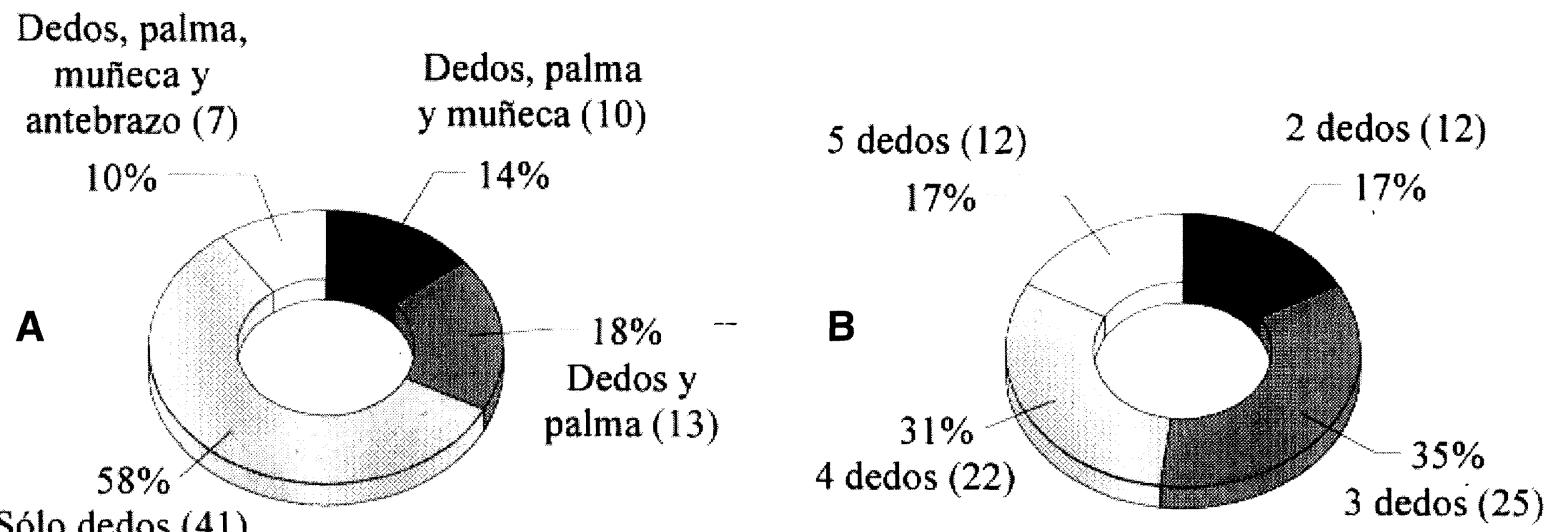

Sólo dedos (41)

Fig. 5. A. Anatomía de las representaciones de manos. B. Número de dedos representados en las manos.

taciones de manos $(46 \%)$ no es posible su determinación. En los 38 casos restantes siempre están presentes el índice y el medio, el anular y el pulgar están representados en la mayoría de los casos ( $92 \%$ y $89 \%$ respectivamente), mientras que el meñique es el menos representado ( $45 \%)$. Debemos considerar que aunque haya sido posible la identificación de los dedos representados, el estado de conservación puede influir en la ausencia de alguno de ellos (Fig. 6 y Tab. 2).

En cuanto a la distribución de manos por paneles, observamos que en 9 paneles (II, III, IV, V, VIII, IX, XIX, XXVI y XXVII) se conserva alguna mano completa, en muchas ocasiones junto a otras incompletas, pero en la mayoría de los casos predominan abundantemente las incompletas (Fig. 7).

Para determinar la lateralidad recordamos que es necesario la presencia del dedo pulgar (será izquierda si la palma está a la izquierda y derecha en caso contrario), por lo que es indeterminada en el $49 \%$

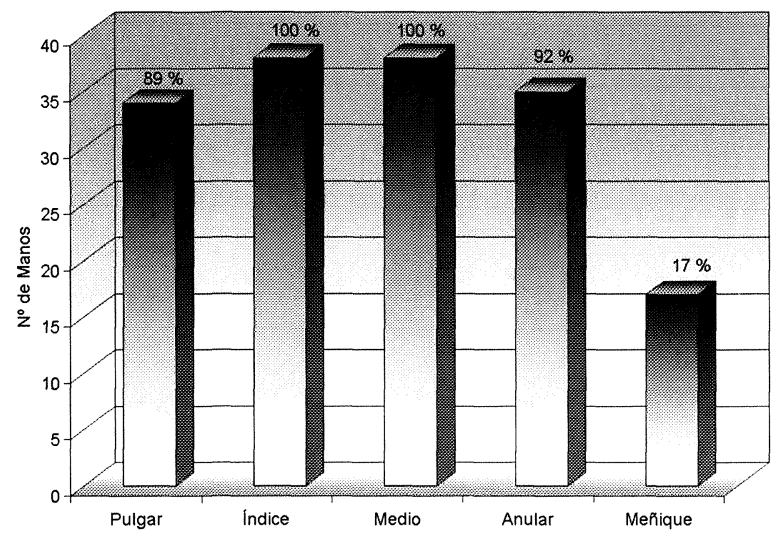

Fig. 6. Gráfico mostrando en número de dedos representados en las distintas manos. de los casos. De las que lo conservan es izquierda en el $30 \%$ de las representaciones y derecha en el $21 \%$ restantes (Fig. 8 y Tab. 2). A. Leroi-Gourhan (1965) sostiene que la lateralidad de las manos no es aleatoria, sino que la dirección de los dedos señala la entrada, salida o algún recorrido específico de la cueva. No es el caso de Maltravieso, que al mostrar un recorrido prácticamente rectilíneo la única dirección posible que podrían señalar es la entrada o salida, pero similar porcentaje de manos se dirigen hacia el final como al principio de la cavidad, y no se disponen en un lado concreto, sino que hay manos señalando hacia el inicio o el final del cavernamiento en ambos laterales.

Respecto a la orientación predomina considerablemente la horizontal con 26 manos, seguida de las inclinadas y de las inclinadas-invertidas, estando representadas las invertidas tan sólo en dos casos. El predominio de manos horizontales, inclinadas o invertidas pudieran haber sido realizadas por dos individuos, uno apoyaría la mano en la superficie mientras el otro procedía a la aplicación del pigmento, mientras que las que muestran orientación vertical tal vez fueran realizadas por la misma persona, que proyectaría el pigmento mientras apoyaba la palma en la pared (Fig. 9 y Tab. 2).

En la realización de las representaciones se seleccionaron superficies más o menos verticales, excepto en dos casos muy significativos en que éstas fueron horizontales (manos 40 y 41 ) y a escasa altura del suelo lo que debió dificultar considerablemente su realización (1). Con una inclinación po-

(1) La estatura estimada para la mano 40 es de $1,55 \mathrm{~m}$, en la número 41 no ha sido posible realizar este cálculo, que podría atribuirse a un individuo infantil o adolescente, hecho que facilitaría su realización si consideramos su potencial mayor flexibilidad. 


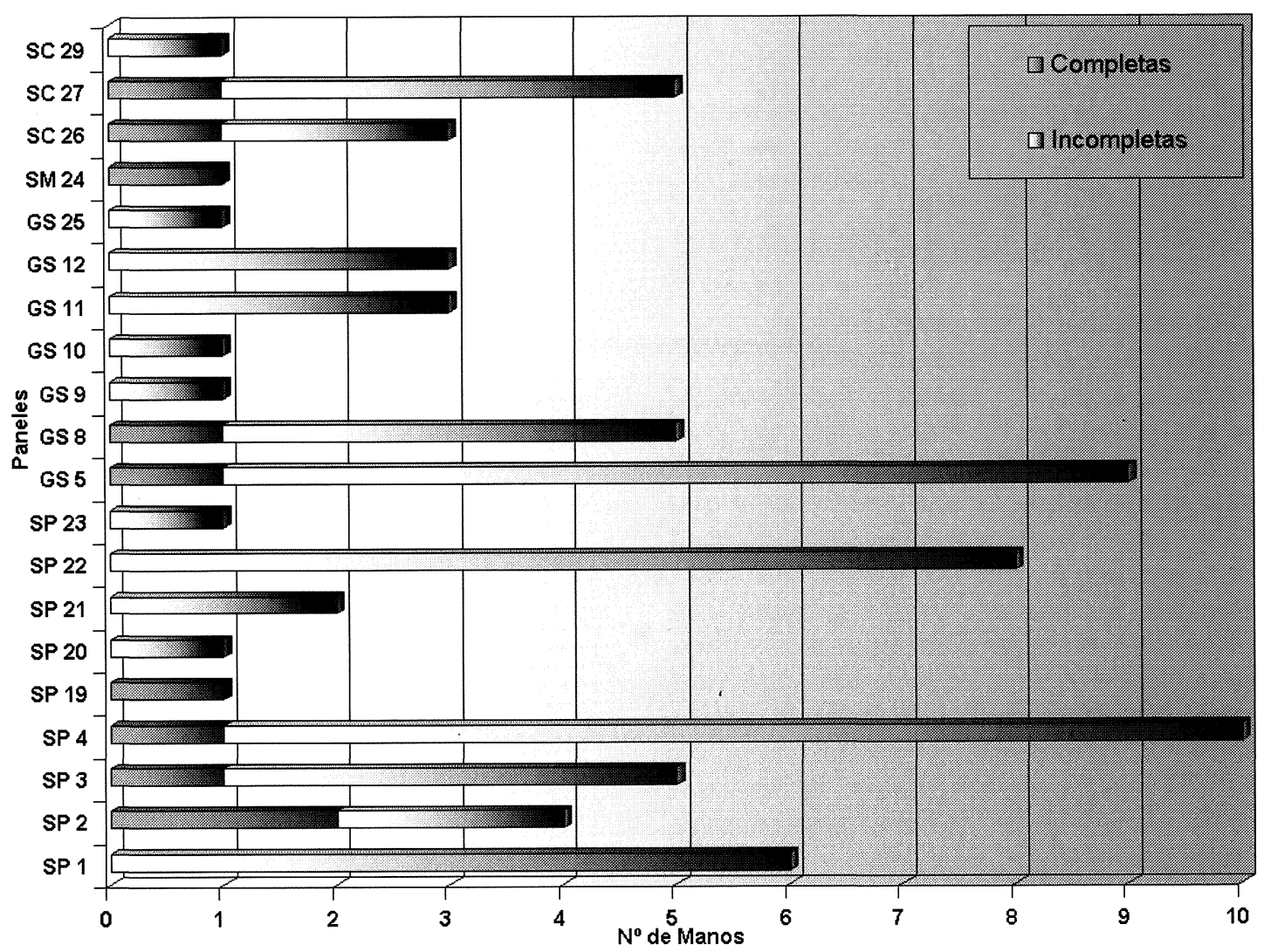

Fig. 7. Gráfico en el que se representa el número de manos completas e incompletas distribuidas por paneles $(\mathrm{SC}=\mathrm{Sala}$ de las columnas; $\mathrm{SM}=$ Sala de la Mesita; $\mathrm{GS}=$ Galería de la Serpiente; $\mathrm{SP}=$ Sala de las Pinturas).

sitiva respecto a la vertical, se disponen la mayoría de los negativos de manos, en 49 casos (69\%), seguidas de las superficies prácticamente verticales, 15 casos $(21,1 \%)$, mientras que 5 manos $(7 \%)$ se disponen en superficies cóncavas (Figs. 8B y Tab. 2). En cuanto a la altura de los paneles con respecto al suelo no se deducen datos significativos puesto que predominan alturas de fácil accesibilidad.

\section{ZOOMORFOS}

De los 29 paneles descritos, hemos documentado figuras zoomorfas en cuatro de ellos.

En el panel número XXVII, que se ubica hacia la mitad de la pared derecha de la Sala de las Columnas, se localiza una figura de animal que aunque fue descrita en investigaciones precedentes no se hizo de forma suficientemente precisa. Tras un detallado análisis, hemos llegado a la conclusión de que, efectivamente, se trata de una figura de ciervo. No es una figura de interpretación sencilla, ya que en ella coinciden dos técnicas diferentes de ejecución, pintura y grabado. La cabeza está silueteada con un trazo de color marrón de apenas $0,5 \mathrm{~mm}$ de anchura que dibuja con bastante precisión astas, testuz, morro y quijada. Las astas representadas en perspectiva semitorcida, ya que se aprecian las dos, se desarrollan en posición vertical mediante sendos trazos ligeramente curvos de los que parten las restantes puntas. Por otra parte la cabeza y el inicio tanto de la línea cérvico-dorsal como del pecho, aparecen realizadas mediante un surco inciso bastante ancho $(0,8 \mathrm{~mm})$ aunque de escasa profundidad y de sección en "U".

En el panel XXVIII hemos documentado una figura de bóvido de color negro (Lám. V), no descrito anteriormente, aunque J.L. Sanchidrián (1988/ 89) identificó en esta zona una línea negruzca.

Hasta nuestra intervención sólo se tenía noticia de una figura zoomorfa grabada, una cierva documentada por E. Ripoll Perelló y J.A. Moure Romanillo (1979) que prácticamente fue ignorado en estudios monográficos posteriores de Maltra- 
Izquierda (21)

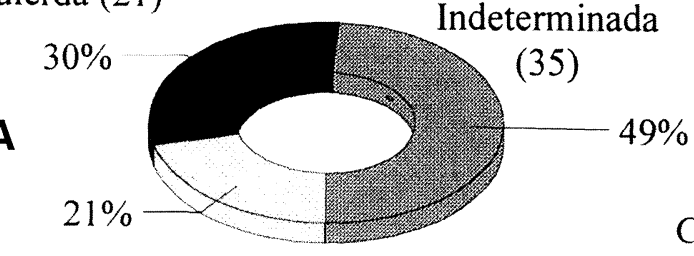

Derecha (15)
Pared

inclinada (49)

Concavidad (5)

Vertical (15)

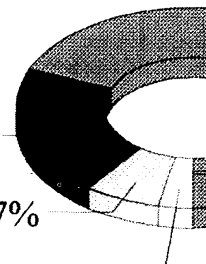

$3 \%$

Fig. 8. A. Lateralidad de las manos representadas. B. Tipos de superficies donde se encuentran las representaciones.

vieso (Sanchidrian Torti,1988/1989). A partir de las investigaciones actuales este repertorio ha aumentado.

En el panel XIII, situado en la Sala de las Chimeneas, aparece el primer grupo de figuras, donde se han podido distinguir tres representaciones zoomorfas. La primera figura puede ser un bóvido de $10 \mathrm{~cm}$ de longitud y $6 \mathrm{~cm}$ de anchura que mira a la

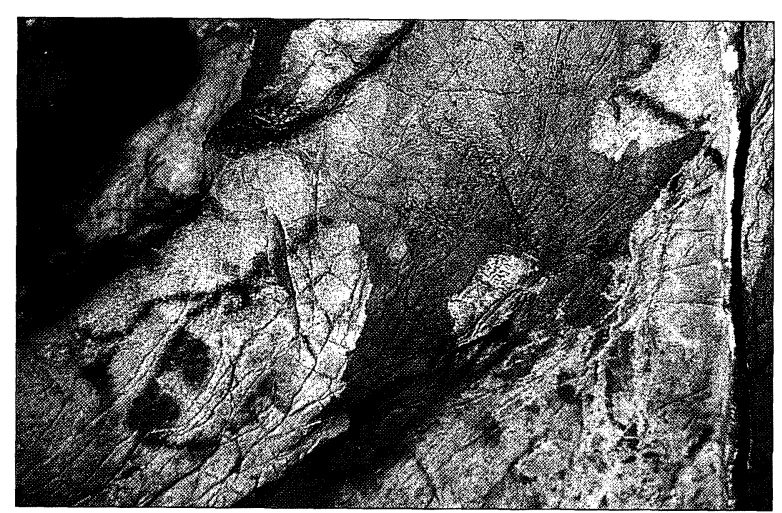

Lám. V. Bóvido hacia la izquierda, pintado en negro.

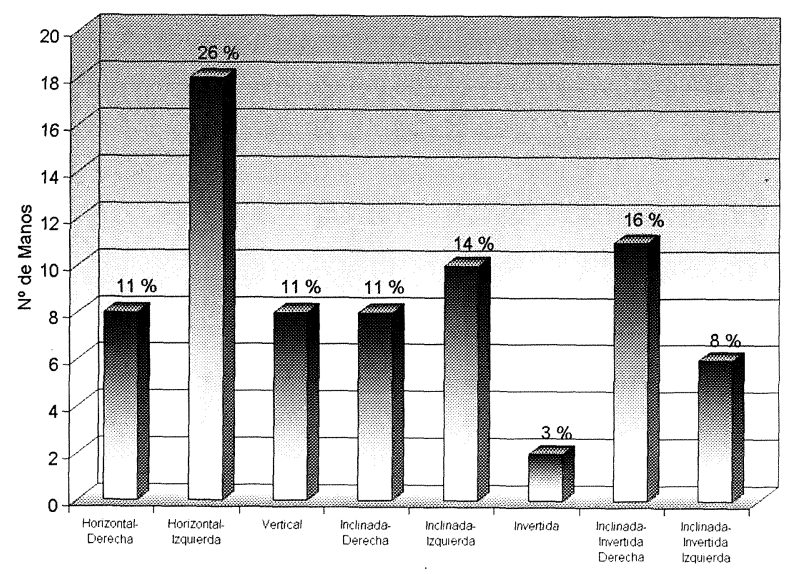

Fig. 9. Orientación predominante que presentan las manos. derecha. Presenta la línea del dorso y la cabeza subrectangular de aspecto muy macizo. Debido a la gran cantidad de trazos verticales que aparecen en esta zona es muy difícil de individualizar la cornamenta.

La siguiente representación es la antes mencionada cierva de $40 \mathrm{~cm}$ de longitud y $15 \mathrm{~cm}$ de anchura. La cabeza muestra tendencia triangular, y en la parte posterior se disponen dos trazos simples hacia atrás que representan las orejas. La línea superior del cuello enlaza sin solución de continuidad con el dorso hasta el arranque de la grupa. Para la realización de la pata trasera se aprovechó un resalte natural de la colada calcítica. El desarrollo del pecho y parte del vientre se solucionan con una sola incisión.

La tercera figura es un cérvido acéfalo, posiblemente una cierva, de $18,5 \mathrm{~cm}$ de longitud y $12 \mathrm{~cm}$ de anchura que mira a la izquierda. Se conserva la línea del pecho, muy bien definida con un trazo bastante profundo, de casi $1 \mathrm{~mm}$, al igual que la pata delantera, que está realizada con sendos trazos paralelos cerrados en la parte final por una línea perpendicular. Aunque el arranque de la línea cérvicodorsal y la del vientre sean muy marcados, van perdiendo profundidad a medida que se alejan del cuello, hasta llegar a ser prácticamente imperceptibles. Actualmente no es posible apreciar la parte trasera, debido a un desconchón de la colada calcítica junto a una bandera. Tal vez se utilizó esta protuberancia para dar volumen al anca y a la pata trasera, hoy desaparecidas. No se observa ningún vestigio de la existencia de la cabeza, aunque la mayoría de los trazos de este panel son de muy escasa profundidad (menor a $0,5 \mathrm{~mm}$ ), por lo que no es difícil que se perdieran por algún proceso erosivo producido en la Sala de las Chimeneas.

En el panel III, descrito por M. Almagro (1960) como el "Camarín de las Manos" también se documentan figuras animales grabadas, que hasta ahora había pasado inadvertid̦as. Así, se ha identifica- 
do un protomos de caprino orientado a la izquierda, de cabeza subrectangular. Las incisiones son de 1 $\mathrm{mm}$ de profundidad y anchura. No se aprecia ningún detalle anatómico del interior de la cabeza, ni el arranque del pecho ni la línea cérvico-dorsal. De la parte posterior arrancan dos trazos paralelos y curvos hacia atrás que representan los cuernos.

Además de estas representaciones indudablemente zoomorfas, se documentan una serie de figuras cuya atribución, debido al estado de conservación, no es tan clara. Tal es el caso de una serie de trazos en el panel XIV de la Sala de las Chimeneas, que podrían interpretarse como una cabeza de caballo entre una serie de signos. Esta posible cabeza de équido había sido descrita como una flecha con punta de aletas o signos diversos, pero su color rojo más intenso que el de las figuras de alrededor y el hecho de que se superponga a aquéllas nos hizo pensar que podría tratarse de otro tipo de representación. Es de pequeño tamaño $10 \mathrm{~cm}$ de longitud por $5 \mathrm{~cm}$ de anchura), y su deficiente estado de conservación nos obliga a ser cautos a la hora de afirmar que se trate, sin lugar a dudas, de un animal.

En esta misma situación se encuentran ciertos trazos que encontramos en los paneles I, XVII, XXII y XXIX, de color rojo, excepto en el panel I que son negros, y en posición horizontal, subparalelos, cóncavos y con tendencia a ser convergentes. Presentan unas dimensiones reducidas, entre 5 y 9 $\mathrm{cm}$, excepto los del panel XXIX, que tienen una longitud de $20 \mathrm{~cm}$. Su configuración y estado de conservación nos inducen a pensar que podrían corresponder a figuras zoomorfas. Otra posibilidad es que configuren pares de líneas como los que se hallan en La Pileta (Benaoján, Málaga), y que han sido interpretadas como huellas de animales (Almagro Basch, 1960).

En muchas zonas de la cueva se localizan diversas manchas de ocre, de las que por el momento no podemos discernir si se corresponden a figuras, signos, restos o simples manchas.

\section{IDEOMORFOS}

Además de manos y zoomorfos, en Maltravieso se documenta un conjunto claro de signos que podemos dividir en cinco tipos:

- trianguliformes (paneles III y XXII);

- puntuaciones (paneles I, II, III, XIV, XXII, XXIII y XXV);

$$
\text { - un "serpentiforme" (panelV); }
$$

- un semicírculo (panel XIV); XIV).

- haces de líneas verticales (paneles VIII y

\section{Trianguliformes}

En el que hemos denominado "panel principal" o número XXII, situado en la pared derecha de la Sala de las Pinturas, encontramos tres triángulos pintados con ocre de color rojo muy vivo e intenso, que ya fueron descritos en investigaciones anteriores. El primero de ellos, en la parte izquierda del panel, es un triángulo equilátero con el vértice hacia arriba y cuyos ángulos laterales se prolongan con una curvatura en la misma dirección, otorgándole un singular aspecto. Sus medidas son de $11 \mathrm{~cm}$ de base por $7 \mathrm{~cm}$ de altura. A la derecha de éste, se dispone otro triángulo de forma más sencilla, sin apéndices, también con el vértice hacia arriba y con unas dimensiones similares: $8 \mathrm{~cm}$ de base por $7 \mathrm{~cm}$ de altura, en peor estado de conservación. Por último a la derecha del panel, bajo la mano número 53 , encontramos un tercer triángulo de características algo dispares a los anteriores, ya que éste presenta prolongaciones de líneas rectas en sus vértices y la base formada con dos concavidades, dando lugar a un nuevo ángulo agudo a la mitad de ésta. Su color es muy similar al de las manos, lo que podría interpretarse que su realización fuera coetánea.

El otro panel en el que se han documentado figuras trianguliformes es el identificado como panel III, donde se observan dos triángulos grabados de morfología casi isósceles, de $11 \mathrm{~cm}$ de longitud y $7 \mathrm{~cm}$ de altura el mayor de ellos, y 10,5 de base y $4,5 \mathrm{~cm}$ de altura el otro. El trazo es bastante somero de $0,5 \mathrm{~mm}$ de profundidad y anchura y de sección en " $\mathrm{V}$ ", aunque debemos considerar que aparece recubierto por la colada calcítica.

\section{Puntuaciones}

Se disponen series de puntuaciones realizadas con pigmentos negros, superpuestas o próximas a otras representaciones, especialmente en el panel XXII de la Sala de las Pinturas, que ya han sido descritas. Fuera de esta sala sólo se han registrado estos elementos en el panel XIV (Sala de las Chimeneas) y en el XXV (Galería entre la Sala de las Columnas y la de la Mesita), siendo en este último caso los puntos de ocre rojo, rompiendo la tónica

T. P., 56, n. ${ }^{\circ} 2,1999$ 
general del conjunto. La mayoría de estas puntuaciones conforman líneas largas, verticales, de trazado irregular y habitualmente varias series paralelas.

\section{Meandriforme o Serpentiforme}

En el centro del panelV, situado en una losa cóncava al principio de la galería a la que da nombre esta figura, se puede observar la única representación de este tipo que existe en la estación, rodeada de cinco manos de factura posterior, ya que puede apreciarse claramente que donde las manos se superponen la figura pierde parte de su color rojo intenso. Se trata de un trazo largo dispuesto longitudinalmente respecto al suelo de forma sinuosa, por lo que tal vez sería más oportuno denominar esta figura como meandriforme y no serpentiforme como tradicionalmente se ha calificado, debido a las connotaciones que este término implica. En su parte inferior el trazo es más concreto y se ondula, terminando en punta.

\section{Semicírculo}

Infrapuesto a la cabecita de caballo del panel XIV antes descrito, en la Sala de las Chimeneas se aprecia un signo compuesto por siete trazos concéntricos semicirculares, actualmente difíciles de definir por su mal estado de conservación. Tiene unas medidas de $15 \mathrm{~cm}$ de longitud por $13 \mathrm{~cm}$ de anchura y está realizada con ocre de color marrón, diferenciándose así del resto de las representaciones de esta estación.

\section{Haces de líneas verticales}

También en el panel XIV y a inferior altura, separados por una pequeña grieta de la pared, encontramos dos series de trazos paralelos y verticales del mismo color que la figura anterior. Se trata de dos series: una más a la izquierda, de siete trazos de $15 \mathrm{~cm}$ de longitud, y otra de dos trazos, con las mismas características que la anterior, pero cuyo pigmento parece ser más intenso. Algo similar se aprecia en el panel VIII, situado en la Galería de la Serpiente: donde se ubican dos trazos verticales paralelos, de $8 \mathrm{~cm}$ de longitud el de la izquierda y 5 el de la derecha, pero en esta ocasión de color negro.

\section{"ASOCIACIONES" ENTRE MANOS Y OTRAS REPRESENTACIONES}

En este apartado nos limitamos solamente a señalar la asociaciones existentes entre las manos y otro tipo de representaciones.

Partiendo de la antigua entrada a la cueva de Maltravieso, Sala de las Chimeneas, la primera asociación entre manos y otras representaciones la encontramos en el panelV ubicado en la Galería de la Serpiente, donde como ya hemos visto aparecen asociadas al meandriforme. En la Sala de las Pinturas las manos se relacionan también con ideomorfos, bien puntuaciones o bien triángulos superpuestos. En el panel III, en el camarín de las manos, éstas se superponen a un caprino y a dos triángulos grabados.

También en la Sala de las Pinturas encontramos en el panel XXIII la asociación más significativa por los temas que contiene. Aparecen cinco manos, una de ellas con antebrazo, junto a varias líneas de puntuaciones negras que se superponen a las mismas y tres trianguliformes pintados en rojo (Lám. VI).

En la Sala de la Mesita aparece una mano aislada, mientras que la situada en el Corredor de la Mesita está asociada a puntos rojos. En la Sala de las Columnas las manos existentes se encuentran de nuevo próximas a zoomorfos, como el cérvido del panel XXVII o el bóvido del panel XXVIII.

Por último, J.L. Sanchidrián (1988/1989) en la pequeña sala de la actual entrada a la cueva identifico tres manos y una línea curva de las cuales nosotros únicamente hemos hallado unos escasos restos pictóricos y otra representación de mano que no se corresponde con las anteriormente descritas.

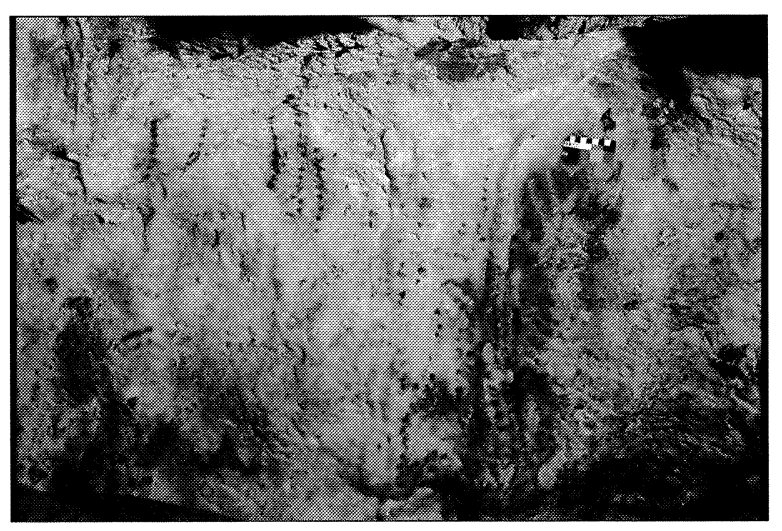

Lám. VI. Vista de conjunto del panel XXII o panel principal en el que se aprecian las distintas figuras en él representadas.

T. P., 56, n. ${ }^{\circ} 2,1999$ 
Posiblemente se deba a las malas condiciones de conservación que presenta la cavidad.

Así podemos inferir, en contra de lo expuesto por F. Jordá (1970) quien afirma que “... las manos se sitúan dentro de un espacio comprendido entre la parte media de la cueva y el pasillo que conduce a la sala con los ideomorfos y las figuras grabadas (Sala de las Chimeneas)", que las manos se distribuyen de la siguiente forma: bien aisladas o bien asociadas en la zona media de la cavidad, pues las tres citadas con anterioridad no se conservan actualmente.

\section{TEORÍAS INTERPRETATIVAS DE LAS REPRESENTACIONES DE MANOS}

Desde el descubrimiento de la cueva de Gargas (Aventignan, Hautes-Pyrénées) a principios de siglo (Cartailhac, 1906a, b), las representaciones de manos con los dedos incompletos o acortados han sido objeto de estudio por gran parte de sus investigadores y han suscitado numerosas hipótesis. Después de haberse propuesto a principios de siglo la teoría de las mutilaciones voluntarias (2), otros investigadores, concretamente médicos aficionados al arte rupestre, propusieron un origen patológico para justificar la ausencia de determinadas falanges de los dedos.

La teoría de las manos con alteraciones morfopatológicas fue defendida fundamentalmente por A. Salhy (1966), quién a su vez se basaba en una propuesta planteada por H. Breuil y E. Cartailhac (1910). Para aquel autor la idea de los dedos flexionados, suscitada por otros investigadores más escépticos, estaba llena de dificultades a causa de las complicadas contorsiones que supuestamente tendrían que adoptar los autores de dichas improntas. Este sería el caso de la posición de algunas manos derechas con el pulgar hacia abajo y con el eje de la misma también dispuesta hacia abajo y hacia la derecha.

Por otra parte, redundaba en que algunas de las mutilaciones se localizan en la zona media de una falange y no a la altura de una articulación interfalángica. Sin embargo, la formación médica de este investigador le permitió proponer un amplio catálogo de enfermedades, a cual más rara (como pue-

(2) El uso del término "mutiladas" implica en sí mismo una toma de posición previa que no compartimos, aunque en las siguientes líneas hagamos referencia en varias ocasiones a dicho término. de ser la trombo-angeiitis obliterante, tipo síndrome de Raynaud), para explicar la ausencia de determinadas partes de los dedos, sobre todo en las cuevas de Gargas y en la vecina cavidad de Tibiran. Con respecto a esta interpretación sorprende el hecho de que en determinadas zonas geográficas, sobre todo de los Pirineos franceses, se concentraran, en un momento de tiempo no excesivamente dilatado, todas las enfermedades y patologías de las extremidades superiores. Más aún si tenemos en cuenta su escasa o nula presencia contemporánea, y sin olvidar otras circunstancias tales como unas condiciones climáticas adversas, una nutrición deficiente o incluso el efecto de la consanguinidad.

En otros casos, los autores defensores de estas sangrientas experiencias, se han basado en la existencia de ciertas huellas negativas en la arcilla blanda de las cuevas de dedos recortados, supuestamente para restañar las heridas. En muchos casos no se ha'tenido en cuenta que muchas de estas supuestas huellas, según ha demostrado el estudio geológico de gran cantidad de ellas, se debían a goteos prolongados de estalagmitas. Por otra parte, también parece extraño que los hombres prehistóricos de Gargas, Tibiran, Cosquer, El Castillo o Maltravieso se dedicaran a restañar las heridas producidas por las amputaciones en la arcilla de las cuevas o mediante la aplicación de ocre rojo o manganeso sobre determinadas zonas de las mismas, donde la escasez de luz para la realización de una operación quirúrgica de este tipo sería otra circunstancia adversa que habría que contemplar.

G.H. Luquet llevó a cabo en 1938 una amplia revisión bibliográfica de las supuestas mutilaciones digitales. Este autor concluye que éstas se podían dividir en dos grandes grupos: a) las causadas por motivos mágico-religiosos como prácticas de duelo-luto, profilaxia contra las enfermedades y la muerte, ritos de paso o ritos propiciatorios, y b) las realizadas por razones mucho más profanas, siendo éste el caso de medios de reconocimiento tribal, mutilaciones ligadas al "esclavismo", castigo de delitos, etc.

L.-R. Nougier (1984) admitía que posiblemente no todas las mutilaciones se debieran a causas patológicas, sino a una serie de amputaciones con un significado ritual. Cita como ejemplo el caso de la treintena de manos de la cueva de Maltravieso "en los Pirineos españoles" (sic), con la mutilación de dos falanges, la media y la distal, únicamente en el dedo meñique, "el menos útil de todos los dedos". Mutilaciones que en éste caso, según A. Sahly

T. P., 56, n. ${ }^{\circ} 2,1999$ 
(1966), sin duda serían de tipo quirúrgico, hecho que le induce a pensar en algún tipo de rito sanguinario.

B. y G. Delluc (1993) consideran que la hipótesis de las manos accidentadas o mutiladas ritualmente "resulta clarísima en Maltravieso, donde 'siempre' falta el dedo meñique". Para A. LeroiGourhan (1964) esta teoría con paralelos etnográficos en países en los que algunas viudas se cortan las falanges distales a la muerte de su marido, se refleja en la bibliografía prehistórica como una curiosa costumbre paleolítica, debiéndose encuadrar las manos mutiladas dentro del capítulo del folklore científico.

Nosotros, siguiendo parcialmente a este último investigador, con el que no estamos de acuerdo en todos sus postulados, pensamos que unos cazadores-recolectores de hace unos 20/30.000 años pudieron en algún caso amputarse los dedos en un rito, con el fin de propiciar un mayor rendimiento cinegético. Pero el hecho de que se repita como un acto consuetudinario no se corresponde con el concepto de economía precaria, en la que la plenitud de facultades era una necesidad perentoria.

Podemos pensar en la existencia de algún tipo de mutilación fortuita bien por causas mecánicas o por congelación de alguna de las falanges, pero su reiteración en ámbitos geográficos tan dispares nos induce a pensar en otras causas mucho menos "sangrientas" para explicar su ausencia, como puede ser la existencia de un código o lenguaje críptico por signos. Entre los esquimales contemporáneos, con un clima tanto o más riguroso que el de la última glaciación, no se sufre este tipo de mutilaciones. Su tecnología y vestimenta se adaptó perfectamente a un medio hostil.Así mismo es de suponer que nuestros antepasados supieron aprovechar con acierto las aptitudes térmicas de las pieles de los animales y de los recursos que les ofrecía el entorno, como demuestra el sensacional hallazgo de Ötzi, el Hombre del Similaun o el Hombre de los Hielos, el cual portaba en el interior de sus botas de piel una espesa capa de heno como aislante para el frío (Spindler, 1993).

Sin embargo, la objeción de mayor peso en contra de estas sangrientas teorías la proporciona el hecho de que no se haya encontrado ningún esqueleto, ni cualquier otro resto óseo aislado encuadrable en el Paleolítico Superior, carente de algunas de las falanges de las manos o de los pies (mucho más sensibles al frío). Tampoco se ha constatado la existencia de deformaciones o amputaciones parciales en estos restos óseos. En cuanto a las llamadas mutilaciones patológicas sorprende que las mismas se produjeran siempre sobre los dedos más largos y NUNCA sobre el dedo pulgar.

Compartimos en líneas generales las teorías de A. Leroi-Gourhan (1967), quien en su momento planteó la posibilidad de interpretarlas como un repliegue intencional de los dedos y, de esta forma, tratarse de un código gestual con algún significado cinegético.Además, este autor observa un orden de frecuencia de aparición de estas mutilaciones, pudiéndose corresponder con las cinco especies de animales más representadas. Este lenguaje, practicado incluso actualmente por los bosquimanos del desierto del Kalahari, es de gran utilidad, ya que permite la comunicación entre los cazadores sobre el tipo de presa que han avistado sin necesidad de articular sonidos que podrían alertar a los animales.

Nosotros, con las importantes novedades que nos ha aportado el descubrimiento de la ocultación intencional del dedo meñique en numerosas representaciones de manos, y retomando en parte la teoría deA. Leroi-Gourhan, creemos que podría interpretarse en efecto como un código, cuyo significado conceptual se nos escapa. Su repetición obedece posiblemente a una intencionalidad manifiesta, como una marca de posesión de un determinado espacio, en definitiva un signo de propiedad que estaría asociado con la ausencia del dedo meñique.

Sin embargo, al mismo tiempo somos conscientes de las limitaciones que esta interpretación tiene. ¿Cómo puede ser que ese mismo código se repita en lugares tan distantes, como son Gargas y Maltravieso, entre otros? Otra objeción a esta teoría es ¿por qué en un código de cinco dedos, el pulgar siempre aparece en su totalidad, limitando las variables combinatorias de dicho código? También sería plausible realizarse otras preguntas: ¿cómo se interpretarían entonces las manos que aparecen completas con todos sus dedos?, ¿por qué aparece siempre la primera falange en todas las representaciones identificadas hasta ahora?, ¿por qué se repinta el dedo meñique en Maltravieso?, ¿por qué la gran mayoría $(98 \%$ ) de las denominadas manos positivas están completas?

Todas las hipótesis a propósito de las manos mutiladas han hecho correr ríos de tinta sin que ninguna de ellas pueda explicar de una manera precisa los hechos observados. Por otro lado, el reciente descubrimiento en Maltravieso de la ocultación intencional del dedo meñique, ya intuida por $\mathrm{F}$. Jordá y J.L Sanchidrián (1992) en la mano del pa- 
nel principal ( $\left.\mathrm{n}^{\circ} 22\right)$, ha sido corroborado fehacientemente por nosotros en otras representaciones de este tipo en la cavidad. Este hecho introduce una nueva variable no contemplada hasta el momento en ninguna otra cueva, que habrá que analizar más extensamente, no sólo referida a esta gruta extremeña, sino también al resto de cavernamientos con este tipo de manifestaciones.

De cualquier forma, su significado sigue siendo desconocido. El intentar dar actualmente una explicación definitiva y absoluta para un símbolo de hace más de 25.000 años, sería por nuestra parte una osadía, ya que no poseemos la piedra de Rosetta que nos pudiera facilitar su interpretación y desciframiento, y además muchos de los datos son desgraciadamente irrecuperables. Parece claro que ya sean autógrafos, signos (según A. Leroi-Gourhan femeninos), símbolos de poder o de posesión, estas representaciones serían posiblemente el testimonio directo de un intento de entrar en contacto con alguna divinidad o el reflejo de un acto intencionado por parte del autor de dejar sobre una pared rocosa la silueta de su herramienta más preciosa y por ende de sí mismo.

Todas éstas son cuestiones en las que, a pesar de los avances que se han producido tanto en este campo de la investigación como en las nuevas metodologías aplicadas a su estudio, el significado de las manos no parece que pueda tener una clara e inmediata solución y permanecerá como otro más de los misterios interpretativos de este arte dejado por nuestros antepasados.

Creemos que en la actualidad, las interpretaciones se encuentran muy influenciadas por trances chamánicos, visiones entópticas y demás hechos relacionados con un mundo mágico o alucinógeno, y a falta de pruebas documentales claras, debemos limitarnos a constatar científicamente su existencia a través de una exhaustiva recogida de todos los datos disponibles, que tal vez permita a nuestros sucesores averiguar el código para descifrar su significado. Esto no quiere decir que íntimamente, cada uno de nosotros pueda pensar que detrás de esas huellas hay algo más.

Lo único que podemos afirmar sin temor a equivocarnos es que las manos son un símbolo unívoco que se repite en lugares muy distantes geográficamente, con cronologías dispares y en culturas muy diversas.

Este tipo de representaciones no sólo se conocen en el arte rupestre paleolítico europeo, fundamentalmente de Francia y España, sino también en manifestaciones más o menos recientes desde Italia hasta Indonesia, entre los antiguos cazadores recolectores de la Patagonia, en las cuevas sagradas de los mayas o en infinidad de abrigos decorados del sur del Sahara. Australia es la isla-continente con mayor número de figuras de manos. Algunas de ellas han sido datadas indirectamente por métodos poco fiables en torno a los 20.000 años B.P., otras son posteriores a la colonización europea y algunas de ellas son incluso subactuales.

\section{PARALELOS DE MANOS EN EL ARTE RUPESTRE PALEOLÍTICO}

Son muy abundantes las estaciones tanto de la Cornisa Cantábrica, como de la zona pirenaica francesa en las que se han documentado representaciones de manos, ya sean en negativo o en positivo, aunque también aparecen en otras áreas del país vecino.

Es sorprendente la diferencia numérica en nuestro país de cavidades que contienen representaciones de manos en proporción a las que se han descrito en Francia. Sin embargo no creemos que este hecho deba de considerarse como un factor competitivo, sino más bien debido a una falta de prospecciones sistemáticas que permitan localizar un mayor número de cuevas fuera de las zonas clásicas. De las ocho cavidades con manifestaciones pictóricas de manos, únicamente tres se sitúan fuera de la Cornisa Cantábrica. Numéricamente es la cueva de Maltravieso, objeto de este artículo, la que presenta un mayor porcentaje de este tipo de figuraciones.

Como síntesis de las manos halladas en la Península Ibérica, podemos concluir que de las setenta y una manos encontradas en la cueva de Maltravieso, salvo tres manos positivas blancas, realizadas con una técnica mixta, el resto de las representaciones se realizan con ocre rojo.

Este predominio del color rojo se constata también en el resto de representaciones que podemos encontrar tanto en España como en Francia.

En España de las ciento noventa y siete manos identificadas (Tab. 3), sin contar las dos supuestas manos de La Pasiega y las dieciséis de Santián, predomina el ocre rojo $(90,35 \%)$ con varias tonalidades, seguidas por las 11 manos con el halo de color marrón $(5,58 \%$ ) de la cueva de La Garma. Con una coloración poco frecuente, encontramos las 4 $(2,03 \%)$ manos en ocre violáceo de la Cueva de

T. P., 56, n. ${ }^{\circ}$ 2, 1999 


\begin{tabular}{|c|c|c|c|}
\hline YACIMIENTO & No MANOS & TECNICA & COLOR \\
\hline Bara-Bahau & Trazos & - & - \\
\hline Font de Gaume & $4-5$ & Negativa & Negras \\
\hline Abri du Poisson & 1 & Negativa & Negro \\
\hline Les Combarelles I & 1 & Negativa & Negra \\
\hline Abri Labattut & 1 & Negativa & Negra \\
\hline Bernifal & $3-4$ & Negativa & Negras \\
\hline Bison & 2 & Negativa & Negras \\
\hline Roc de Vézac & 2 & Negativa & Ocre rojo, negro \\
\hline Moulin de Laguenay & 2 & Negativa & Negras \\
\hline Bourgnetou & 1 & Positiva & Negra \\
\hline Les Fieux & 6 & Negativa & Ocre rojo, negro \\
\hline Les Merveilles & 6 & Positiva-Negativa & Ocre rojo, negro \\
\hline Roucadour & $10-9$ & Negativa & Ocre rojo, negro \\
\hline Pech Merle & 16 & Negativa & Ocre rojo, negro \\
\hline Baume-Latrone & 5 & Positiva & Ocre rojo \\
\hline Bayol & 6 & Positiva & - \\
\hline Cosquer & 46 & Negativa & Ocre rojo, negro \\
\hline Erberua & 3 & Negativa & Ocre rojo, marrón, negro \\
\hline Gargas & 231 & Negativa & Ocre rojo, marrón, humo, \\
& & & negro, blanco \\
\hline Tibiran & 18 & Negativa & Ocre rojo, gris \\
\hline Cougnac & 1 & Negativa & - \\
\hline Trois-Fréres & 5 & Negativa & Ocre rojo \\
\hline Cheval & Trazos de dedos & Grabado & - \\
\hline Le Portel & Trazos de dedos & - & Ocre rojo \\
\hline Bédeilhac & 2 & Positiva & Ocre rojo, negro \\
\hline Oxocelhaya & Trazos de dedos & - & - \\
\hline Tito Bustillo & 1 & Negativa & Ocre rojo \\
\hline La Fuente del Salin & 14 & Negativa Positiva & Ocre rojo, negro \\
\hline Altamira & 6 & Negativa Positiva & Ocre rojo, violáceo \\
\hline El Castillo & 56 & Negativa & Ocre rojo \\
\hline Cudón & 1 & Negativa & Ocre rojo \\
\hline La Garma & 32 & Negativa & Ocre rojo, marrón \\
\hline La Fuente del Trucho & 15 & Negativa & Ocre rojo \\
\hline Ardales & 1 & Negativa & Negro \\
\hline & & & \\
\hline & 1 & & \\
\hline & 1 & & \\
\hline & 1 & & \\
\hline & & & \\
\hline & & & \\
\hline
\end{tabular}

Tab. 3. Tabla de las manos representadas en estaciones francesas y españolas, así como del color y la técnica con que fueron realizadas.

Altamira y pintadas con una técnica mixta, única en el arte rupestre paleolítico, hallamos las 3 siluetas-improntas $1,52 \%$ ) de la cueva de Maltravieso. Por último y con una escasa representatividad, está la mano negra aislada $(0,50 \%)$ de la Cueva de Ardales.

En el país vecino, no se mantiene esta relación, ya que de las trescientas cuarenta y dos manos donde se ha podido identificar el color, ciento veintisiete $(37,1 \%)$ son de color rojo, doscientas cinco $(59,9 \%)$ de color negro. Siete se realizan con ocre marrón, dos con ocre rojo amarillento y una última mano es de color blanco.

En Francia se ha podido determinar en trescientas cuarenta y dos representaciones la técnica con que fueron elaboradas. De éstas, trescientas treinta y cuatro $(97,66 \%)$ son negativas y tan sólo ocho $(2,33 \%)$ son manos positivas.

Donde sí se aprecia una consonancia entre las representaciones encontradas en la cueva de Maltravieso y el resto de las representaciones analizadas anteriormente es en la técnica con que fueron realizadas. Como ya se ha dicho, de las 71 manos localizadas en la cueva cacereña, salvo tres, que tienen una técnica mixta, el resto están realizadas en negativo. En España podemos comprobar que de las ciento noventa y siete manos ya mencionadas la gran mayoría, $193(97,96 \%)$ son negativas y sólo cuatro $(2,03 \%)$ han sido plasmadas en positivo.

\section{UNA PROPUESTA CRONOLÓGICA PARA LAS MANIFESTACIONES DE MALTRAVIESO}

El intentar establecer un marco cronológico para las diferentes representaciones pictóricas halladas en la cueva de Maltravieso es una tarea complicada, ya que no existen superposiciones que abarquen todas las manifestaciones. Por otra parte el intento realizado para obtener una datación radiométrica de una de las puntuaciones negras superpuestas en forma de haces a todas las representaciones de manos no nos proporcionó ningún resultado, ya que el pigmento analizable no era carbón vegetal sino manganeso mineral.

Esta imposibilidad de conseguir una fecha que posibilitara una datación post quem de la mayor parte de las manos, nos ha llevado a intentar establecer una cronología diacrónica basada en la sucesión iconográfica. Estratigráficamente, las sucesiones de pictogramas únicamente se pueden constatar fehacientemente en el llamado "Camarín de las Manos", aunque para determinadas fases de la secuencia hemos tenido que recurrir al panel $\mathrm{V}$ de la Galería de la Serpiente o al panel XXII de la Sala de las Pinturas.

\section{$1^{\text {a }}$ Fase}

En la base estratigráfica se sitúan las manifestaciones profundamente incisas correspondientes a un protomos de caprino y dos triángulos yuxtapuestos recubiertos por una colada estalagmítica del panel III. Para los ideomorfos, tradicionalmente asociados a símbolos femeninos, se conocen abundantes paralelos cuya atribución cronológica generalmente se sitúa en los primeros estadios de las manifestaciones rupestres dejadas por nuestros antepasados. Así recurriendo al cuestionado sistema cronológico basado en las características estilísticas de A. Leroi-Gourhan, estas figuras que se encuadrarían en el Estilo I, deben adscribirse al Auriñaciense. Son numerosos los testimonios de este tipo de manifestaciones, asociados generalmente a conceptos de fertilidad y fecundidad, como por ejemplo el conocido bloque calizo de La Ferras- 
sie (Dordogne) descubierto en 1911 por D. Peyrony (1934) en un nivel arqueológico fechado en el entonces llamadoAuriñaciense III, y que en la actualidad se corresponde con un Auriñaciense Medio. Otro resto paralelizable con estas formas triangulares, es el bloque calcáreo hallado por L. Didon (1911) en el nivel Auriñaciense Medio del Abri Blanchard (Dordogne), en el que se distinguen algunos triángulos que se han identificado como vulvas femeninas.

Sin embargo en esta fase estilística son extremadamente raras las representaciones de zoomorfos. El caprino, toscamente representado, posee unas características morfoestilísticas más propias de representaciones del Estilo III, pero el recubrimiento calcítico y la proximidad con los triángulos, por otra parte ausentes en esta fase estilística avanzada, nos lleva proponer para estas manifestaciones una cronología encuadrable en elAuriñaciense MedioFinal.

\section{$2^{\mathrm{a}}$ Fase}

Para este segundo estadio, debemos recurrir al panel V del Corredor de la Serpiente en el que se aprecia claramente la figura de un meandriforme que se encuentra infrapuesta a tres de las manos negativas que se distinguen en esta superficie y por lo tanto debe de ser anterior en su ejecución, sin descartarse su posible simultaneidad. Dado que carecemos de unos criterios cronológicos más precisos, lo único que podemos evidenciar es su posición estratigráfica intermedia entre la fase (1) de las figuras profundamente incisas y la fase (3) de las siluetas de manos. Según F. Jordá y J.L. Sanchidrián (1992) esta figura "ofrece una cronología más precisa....., figura que tiene un amplio desarrollo en toda la península durante el Magdaleniense medio". Aparentemente esta afirmación, como veremos a continuación por la cronología de las manos no se puede generalizar.

\section{$3^{\mathrm{a}}$ Fase}

Tras un largo abandono de la cueva, aunque el lapso de tiempo no se puede fijar con exactitud debido a las diversas variables que se pudieron producir como pueden ser la cantidad de precipitaciones, el volumen de agua filtrada, etc., durante el cual se formó la colada estalagmítica que recubre las figu- ras antes descritas, se realizó el conjunto de las manos, aparentemente, sólo interrumpido por la realización del meandriforme. Teniendo en cuenta su similitud morfométrica, coloración y distribución espacial en la cavidad, creemos que todas ellas poseen una unidad cronocultural que puede ser más o menos dilatada, pero que por paralelismos con otros conjuntos se puede fechar en el Perigordiense o Gravetiense.

A pesar de la abundancia de testimonios de manos en el arte rupestre, solamente contamos con dos dataciones radiocarbónicas directas para una de estas representaciones. Se trata de una de las manos silueteada en negro de la Grotte Cosquer (Bouchesdu-Rhône) (Clottes y Courtin, 1994). La muestra de carbón antes mencionada fue analizada dividiéndola en dos partes que proporcionaron las fechas de $27110 \pm 390 \mathrm{BP}$ (GIFA92409) para la primera mitad y de $27110 \pm 350$ BP (GIFA92491) para la segunda mitad, lo que nos sitúa coherentemente en un horizonte cultural gravetiense.

A lo largo de la historia de la investigación de la Grotte de Gargas (Hautes-Pyrénées) diversos autores propusieron la hipótesis de que las manos y las series de grabados pudieran ser contemporáneos, teniendo en cuenta que las figuras incisas habían sido encuadradas por sus paralelos en objetos de arte mueble en un horizonte cultural Perigordiense Superior o Gravetiense (Nougier, 1984). Pero recientemente esta cueva ha entrado a formar parte de las estaciones con figuras rupestres datadas por métodos físico-químicos. A pesar de que algunas manos negativas están pintadas con el halo de color negro, el análisis de pigmentos demostró que éstas se habían realizado con manganeso (Clot et alii, 1995) y por tanto no podían ser fechadas. Pero a raíz del descubrimiento de la cueva submarina del Cap Morgiou, y con el fin de paralelizar las manos en ella encontradas, se volvió a revisar la cavidad pirenaica permitiendo a J. Clottes efectuar el sensacional hallazgo de unas pequeñas esquirlas de hueso en una de las grietas de la cueva muy próxima a una de las manos situada en el panel IV de la sala I. Una vez analizados estos restos óseos mediante el acelerador de partículas se obtuvo una datación de 26860 \pm 460BP (GIFA92369) (Clottes et alii, 1992).

De forma indirecta poseemos otra datación radiométrica, en este caso para la cueva de La Fuente del Salín (Cantabria). Esta cueva tiene una unidad temática restringida a representaciones de manos y el yacimiento hallado en el interior de la

T. P., 56, n. ${ }^{\circ} 2,1999$ 
cavidad sólo posee un nivel arqueológico. Precisamente en este estrato se encontró un hogar que fue datado en $22340 \pm 510 / 480 \mathrm{BP}(\mathrm{GrN} 18574)$ (Moure Romanillo y González Morales, 1992). Si tenemos en cuenta que se trata de un conjunto cerrado se puede inferir que el hogar estuvo encendido cuando se pintaron las manos y por lo tanto la fecha de las mismas debe de ser similar a la del hogar.

Como podemos comprobar poco a poco se van concretando las fechas y confirmando las suposiciones del abate $\mathrm{H}$. Breuil (1952) que ya situaba las siluetas de manos entre las manifestaciones más antiguas del arte pleistoceno. En su ordenación cultural, basada en el análisis de las superposiciones, las manos se encuadraban en el llamado ciclo auriñaco-perigordiense. Esta clasificación se fundamentaba en la minuciosa observación de cientos de paneles decorados como los de las cuevas de Font de Gaume o El Castillo, en los que las improntas de manos siempre estaban infrapuestas al resto de las figuras, ya fueran grabadas o pintadas.

El gran número de manos en negativo de la cueva de El Castillo (Cantabria) se sitúan siempre infrapuestas al resto de las figuras que aparecen en los diferentes paneles. Recientemente, en el marco de dos proyectos de investigación para obtener dataciones y realizar estudios en diversas cavidades de la Cornisa Cantábrica, se han conseguido fechar dos representaciones zoomorfas de esta cueva de la vega del Pas. Se trata por un lado del bisonte bícromo situado en la gran sala de la entrada y que recubre cuatro manos negativas en ocre rojo. Para esta figura la fecha obtenida es de $12910 \pm 180 \mathrm{BP}$ (GIFA91172). Relativamente cerca de esta figura, se ha datado otro bisonte bícromo para el que la fecha es de $13060 \pm 200 \mathrm{BP}$ (GIFA91004) y que en este caso sólo se superpone a una mano en negativo (Valladas et alii, 1992).

Como vemos las mediciones radiométricas sitúan con bastante precisión estas dos figuras zoomorfas en un horizonte cultural Magdaleniense Mèdio regional (Moure Romanillo et alii, 1996). Es evidente que no se pueden correlacionar los dos tipos de manifestaciones, ni tampoco excluir la posible contemporaneidad de las mismas, pero teniendo en cuenta la diferencia de coloración, así como el estado de conservación de las siluetas de manos, dicha sincronía a nosotros, nos parece cuando menos dificultosa, considerando como más plausible una cronología más antigua.

Algo similar ocurre con la cueva de Altamira (Santillana del Mar, Cantabria), aunque en este caso la superposición de las figuras fechadas no es tan directa como en el caso antes descrito. En el estudio inédito todavía de las diferentes figuras del techo de Altamira, encargado por el prof. F. Bernaldo de Quirós entonces, director del Centro y Museo de Altamira, pudimos comprobar que los estudios realizados con anterioridad no se habían llevado a cabo directamente en la cavidad (Jordá Cerdá, 1972), sino basándose en los dibujos del abate Breuil (Breuil y Cartailhac, 1906), que sin embargo están cargados de errores al haberse realizado a mano alzada y haber compuesto las láminas a distancia. En síntesis la secuencia pictórica constatada es la siguiente: existe una primera etapa de grabado en la que se asocian elementos figurativos (ciervos y peces) y diseños abstractos (las llamadas chozas que nosotros creemos que representan vellos púbicos), seguida por un segundo momento esencialmente pictórico y figurativo sin aparente relación con la fase precedente. En esta segunda fase, cabría señalar la presencia -y por este orden-de:

a) siluetas negras perfiladas

b) contornos grabados de los grandes bisontes

c) bícromos (o polícromos)

d) dibujos naturalistas grabados (ciervo bramando y antropomorfos)

Contrariamente a lo que se ha señalado en varias ocasiones una parte de estos bícromos se encuentran infrapuestos a los claviformes.

Estos signos rojos femeninos (llamados claviformes) de color carmín y que constituyen la tercera etapa, se distribuyen a lo largo de la zona sureste de la sala recubriendo frecuentemente a los dibujos grabados de chozas o vellos púbicos que indicaban el inicio de la frecuentación artística del lugar. Esta fase puede asociarse por lo menos desde un punto de vista cromático a los llamados caballos chinos realizados así mismo en color carmín.

Existe una cuarta etapa, escasamente representada, de figuras contorneadas con pigmentos de color violáceo cuya posición cronológica en términos relativos, contrariamente a lo expuesto con anterioridad, cabe atribuirla a una fase posterior a la pintura carmín -es el caso de las manos en negativo sobre los denominados caballos chinos-y por consiguiente también después de los bícromos.

Por último, el detallado examen de este techo, revela la existencia de una serie de figuraciones grabadas que constituyen una quinta etapa, entre los que destaca el grupo de 9 antropomorfos (Breuil y Obermaier, 1935: 72-76; Ripoll Perelló, 1957- 
58). Éstos no han podido ser relacionados con las fases antes descritas ya que estas representaciones al igual que otros grabados, básicamente de cérvidos, no aparecen infrapuestos o superpuestos a ningún otro motivo.

Esta sucinta descripción nos demuestra que en el caso de la llamada Capilla Sixtina delArte Cuaternario, las manos no se sitúan en la base pictórica sino todo lo contrario. Se han obtenido varias dataciones de C14 para varios de los zoomorfos del techo. La primera de ellas es de $13570 \pm 190 \mathrm{BP}$ (GIFA91178) y corresponde al pequeño bisonte silueteado en negro en la zona central del techo, próximo a la cabeza del gran bisonte estático bícromo. Para los llamados bisontes polícromos se han realizados dos dataciones, una de ellas en el gran bisonte bícromo hacia la izquierda, en el centro exacto del techo, ha proporcionado una fecha de $13940 \pm 170$ BP (GIFA91179). Otra muestra extraída del lomo de gran bisonte polícromo en posición estática y orientado hacia la derecha ha dado una cronología de $14330 \pm$ 190BP (GIFA91181) (Moure Romanillo et alii, 1996; Valladas et alii, 1992).

Si tenemos en cuenta estas mediciones radiocarbónicas, podemos comprobar que las grandes manifestaciones de bisontes en Altamira son ligeramente anteriores a las de El Castillo y por lo tanto se sitúan en un Magdaleniense Medio. En relación con las figuras de manos que, como ya hemos visto antes, se sitúan prácticamente al final de la secuencia pictórica, es evidente que en este caso son posteriores a los zoomorfos y por lo tanto, sin excluir una relativa contemporaneidad, deben de atribuirse culturalmente a un Magdaleniense Superior.

Como conclusión a esta segunda fase pictórica de Maltravieso podemos decir que salvo algunas excepciones como el caso de la cueva de Altamira o el resto de estaciones que no han podido ser fechadas, si tenemos en cuenta la coherencia del conjunto de dataciones que poseemos para siluetas de manos, es posible incluir las de la cueva cacereña en un horizonte cultural gravetiense, aunque no se conozca por el momento ningún yacimiento atribuido a esta época en la zona.

\section{$4^{\mathrm{a}}$ Fase}

Al igual que ocurría en la segunda fase, para explicar esta, debemos referirnos a otro conjunto de representaciones que no se encuentran en el panel III o Camarín de las Manos, sino en el panel XXII o panel principal. En una posición secuencial intermedia entre las siluetas de manos y la quinta fase en la que se representan los haces de puntuaciones negras, sobre la superficie antes descrita, se trazaron tres ideomorfos trianguliformes. Estas figuras pintadas, en ocre rojo carmín muy intenso y con diferentes características morfométricas, se sitúan por encima del halo de varias manos e infrapuestos de forma evidente a las serie de puntos. Para establecer su cronología se ha recurrido en varias ocasiones (Almagro Basch, 1969; Jordá Cerdá y Sanchidrián Torti, 1992) a paralelismos con otras cavidades de la Cornisa Cantábrica o con la cueva de La Pileta (Benaoján, Málaga). Esto ha hecho suponer a estos autores que tales figuras se debieron realizar durante etapas ya avanzadas del arte paleolítico (Jordá Cerdá, 1970). Nosotros no creemos que exista una base sólida sobre la que sustentar un encuadre cronológico o una interpretación de estos triángulos, simplemente podemos explicitar su posición intermedia en esta secuencia.

\section{$5^{\mathrm{a}}$ Fase}

En la capa superior de la seriación pictórica del Camarín de las Manos, se distinguen claramente dos haces de líneas de puntuaciones negruzcas. En este caso tampoco podemos precisar el lapso de tiempo transcurrido desde que se plasmaran las siluetas de manos, o en el caso del panel XXII, desde que se realizaron los triángulos. La única circunstancia constatada es que estos trazos discontinuos negros siempre se superponen a las manos en todos los paneles. Como ya decíamos al principio de este capítulo, tomamos dos muestras de sendas puntuaciones con el fin de conseguir una datación. Un análisis preliminar del pigmento nos constató que se trataba de manganeso y que por lo tanto no se podía efectuar la datación. Una vez enviadas las muestras y cuando estabamos analizando en detalle la documentación fotográfica, fundamentalmente las diapositivas con película infrarroja, comprobamos que las mencionadas digitaciones negras no respondían al espectro lumínico, hecho que nos puso sobre la pista de que podría tratarse de un pigmento inorgánico.

Todas estas superposiciones de las puntuaciones sobre las manos se han podido constatar en otros paneles, como por ejemplo en los identificados con

T. P., 56, n. ${ }^{\circ}$ 2, 1999 
los números XXII y XXIII de la misma Sala de las Pinturas. Leroi-Gourhan (1964) asociaba en su interpretación dicotómica estas series de puntos con signos masculinos, pero como en su momento escribía M. Almagro (1969) "sobre su significación segura es difícil dar una solución válida".

\section{$6^{\mathbf{a}}$ Fase}

Por último, sin una correlación evidente con las series superpuestas, encontramos otro conjunto de manifestaciones difícilmente correlacionables con el resto. Se trata del panel XIII con grabados de trazo fino de la Sala de las Chimeneas, el panel XIV con un protomos de équido pintado en ocre rojo y un ideomorfo semicircular, también pintado en ocre marrón-beige, así como los paneles XXVII y XXVIII de la Sala de las Columnas con sendas representaciones pintadas de un ciervo y un bóvido.

Cada una de estas figuras posee de manera independiente una técnica y un estilo diferente en cuanto a su realización. Sin embargo estas mismas características estilísticas nos llevan a proponer un estadio bastante más avanzado que el de las manos, posiblemente paralelizable con la fase de las puntuaciones negruzcas. En el caso de los grabados filiformes creemos que las características estilísticas, ya evidenciadas en otros conjuntos situados en la zona sur de la Península Ibérica, como pueden ser las líneas cérvico-dorsales muy marcadas, la ausencia de detalles en las extremidades o de otros caracteres morfológicos, junto con las cabezas muy alargadas, se pueden situar en el habitual Estilo III-IV de A. Leroi-Gourhan. Hacemos hincapié en el hecho de que la gran mayoría de los grupos artísticos descubiertos en esta zona geográfica poseen unas características similares, difíciles de encajar estrictamente en alguno de los estilos propuestos, hecho que nos hace pensar en la posibilidad de establecer un nuevo estilo, el ibérico o extracantábrico que podría incluirlos a todos.

En uno de los casos esta circunstancia es plausible dado que, a falta de un análisis de pigmentos, el bóvido pintado en negro se puede correlacionar con las puntuaciones negras superpuestas a las manos. Si este hecho se constatara, posiblemente podríamos incorporar a este último estadio de manifestaciones aquellas representaciones incisas o pintadas que antes mencionábamos.

El establecer un marco cronológico para la cueva de Maltravieso resulta extremadamente complejo, precisamente por la ausencia de representaciones zoomorfas características que por lo menos nos permitan hacer un encuadre estilístico. En definitiva, comprobamos que existe un primer y fugaz momento encuadrable en el Auriñaciense Medio o Final. Una segunda fase igualmente esporádica, previa a la plasmación de las manos que se corresponde con la tercera fase, la más importante, y situada posiblemente en un horizonte cultural gravetiense. Posteriormente se documentan otras pictografías cuya cronología es aún más imprecisa si cabe, aunque creemos que se posicionaría en un momento transicional entre el Solutrense Final y el Magdaleniense Inicial (Tab. 4).

Esperamos que en un futuro próximo las técnicas de datación avancen sustancialmente y permitan la posibilidad de fechar otros materiales que no sólo sea el carbón. Sin duda el realizar una excavación en la Salà de las Chimeneas nos proporcionaría, de existir un yacimiento, la posibilidad de encuadrar con una mayor fiabilidad el conjunto de representaciones de esta cueva cacereña.

\section{CONCLUSIÓN}

A lo largo de las páginas precedentes hemos podido apreciar la calidad e importancia de las representaciones de la cueva de Maltravieso fundamentalmente de manos. Esta significación viene dada no sólo por el hecho de hallarse aislada en una zona geográfica en la que únicamente desde hace unos pocos años se conoce otra estación con representaciones superopaleolíticas. Nos referimos a la cueva de la Mina de Ibor (Castañar de Ibor, Cáceres), que es una pequeña cavidad de poco más de treinta metros de profundidad. Las representaciones aparecen en las únicas superficies aptas para contener grabados, sobre una pequeña superficie vertical de la pared derecha, a unos $15 \mathrm{~m}$ de la entrada y a 90 $\mathrm{cm}$ del nivel actual de suelo.

Los grabados documentados son: dos cérvidos, dos équidos, un posible oso y dos cuadrúpedos indeterminados, además de otros trazos inconexos que no conforman ninguna figura identificable. Este repertorio figurativo sigue la corriente iconográfica de las estaciones con manifestaciones de arte paleolítico extracantábrico. La fauna documentada, fundamentalmente caballos y ciervos, incluye sin embargo, un animal que aparece escasamente representado en el arte Cuaternario, como es 


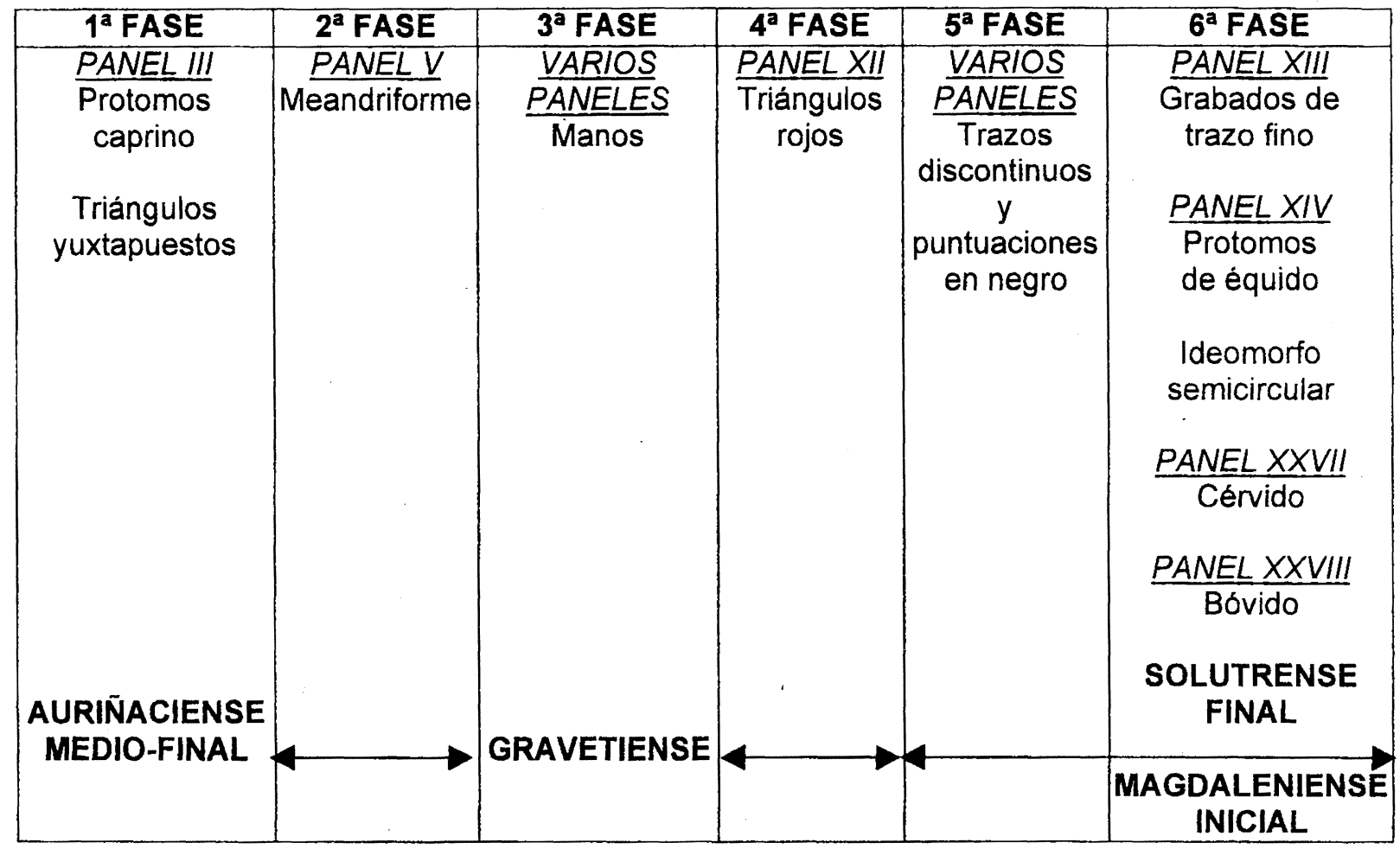

Tab. 4. Cuadro-resumen de la propuesta cronológica de las distintas representaciones.

el oso (Ripoll López y Collado Giraldo, 1996, 1997; Ripoll López et alii, 1997).

Todas las figuras se realizaron mediante grabado lineal de sección en "U" o "V", muy fino y con escasa profundidad. El surco del grabado se encuentra totalmente patinado y recubierto por una fina capa de la colada calcítica, elemento que unido a las características estilísticas induce a situar estas figuras en un momento final del Paleolítico Superior. Así, y centrándonos en la representación del ciervo, podemos ver como mediante un único trazo se ha conseguido realizar la parte anterior del ciervo (desde la cuerna hasta el pecho pasando por la cabeza), esta convención estilística se ha observado repetidamente en figuras cuya adscripción se corresponde con un momento inicial del Magdaleniense.

La importancia de la Mina de Ibor radica en su posición geográfica, ya que se sitúa en una zona en la que la única estación superopaleolítica conocida hasta el momento era la Cueva de Maltravieso, por lo que representa un importante hito en el estudio del arte rupestre a pesar de sus reducidas dimensiones y de su pequeño panel inciso.

En los alrededores de la ciudad de Cáceres se conocen otras cavidades como la cueva de Santa Ana que ya fue prospectada en su momento por $\mathrm{M}$.
Almagro Basch (1969: 14) y también por C. Callejo (1981) que además cita otras cavernas en el llamado calerizo de Cáceres como son la cueva de El Conejar y la de La Becerra. En nuestro afán por encontrar otras manifestaciones artísticas similares a las de Maltravieso con el fin de realizar un encuadre cronoestilístico pluriestacional, hemos prospectado todas estas cavidades añadiendo además un nuevo cavernamiento colmatado que en la zona se conoce bajo la denominación de cueva de El Oso.

Prescindiendo de los trabajos anteriores y con el fin de asegurarnos que no existía ningún resto pictórico o inciso y tampoco arqueológico, después de obtener los permisos correspondientes, pudimos acceder a la mencionada cueva de Santa Ana. Después de una revisión exhaustiva de las superficies, únicamente hemos hallado un pequeño panel con incisiones que no presenta ninguna figura reconocible, limitándose a simples trazos verticales atravesados perpendicularmente por otros surcos y algunas líneas curvas. Este descubrimiento, lo avanzamos aquí con muchas reservas, a falta de un análisis más detallado ya que no descartamos encontrar otros restos en esta gran cavidad con numerosas galerías e incluso un sifón que suponemos que bloquea el acceso a otros sectores de la cavidad. 
En definitiva comprobamos que la única cavidad con un elenco de manifestaciones lo suficientemente amplio para poder establecer unas conclusiones, es la cueva de Maltravieso. A modo de síntesis o colofón al texto presentado, podemos concretar que en la actualidad se conocen 71 representaciones de manos que se incluyen en el presente trabajo, más otra inédita que se incorporará en breve tras su estudio directo.

Esperamos y deseamos que tanto los trabajos científicos, como las inversiones económicas que están realizando las administraciones públicas, ya sea en la propia cueva o en el entorno inmediato, supongan la recuperación definitiva de Maltravieso para la ciencia prehistórica y para la ciudad de Cáceres. También esperamos que las prospecciones intensivas que se están llevando a cabo en la zona extremeña tanto española como portuguesa, nos aporten nuevos datos que permitan ampliar el número de estaciones con manifestaciones rupestres y otros yacimientos encuadrables en el Paleolítico Superior que nos ayuden a posicionar con más precisión el repertorio pictórico de la cueva de Maltravieso.

\section{BIBLIOGRAFÍA}

Almagro Basch, M. (1960): "Las pinturas rupestres cuaternarias de la Cueva de Maltravieso en Cáceres". Revista de Archivos, Bibliotecas y Museos, Madrid, LXVIII, 2: 665-707.

Almagro BASCh, M. (1969): Las pinturas rupestres de la Cueva de Maltravieso, en Cáceres. Guía del visitante. Ministerio de Educación y Ciencia, Dirección General de Bellas Artes y Ayuntamiento de Cáceres. Madrid.

BreuiL, H. (1952): Quatrè cents siècles d'art pariètal. Les cavernes ornées de l'Age du Renne. Edit. Windels. Montignac.

Breuil, H. y CARTAILHAC, E. (1906): La caverne d'Altamira à Santillane près Santander (Espagne). Imp. de Monaco.

Breuil, H. y Cartailhac, E. (1910): "Les peintures et gravures murales des cavernes pyrénéennes. IV: Gargas, commune d'Aventignan (Hautes-Pyrénées)". L'Anthropologie, 21: 149-150.

Breuil, H. y Obermaier, H. (1935): The Cave of Altamira at Santillana del Mar, Spain. Junta de las cuevas de Altamira, Hispanic Society of America y Academia de la Historia. Madrid.

Callejo Serrano, C. (1958): La cueva prehistórica de Maltravieso junto a Cáceres. Publicaciones de la Biblioteca Pública de la Ciudad. Cáceres.

Callejo Serrano, C. (1970): “Catálogo de las pinturas de la Cueva de Maltravieso". XI Congreso Nacional de Arqueología (Mérida, 1968): 154-174, Zaragoza.

Callejo Serrano, C. (1981): "El símbolo de la mano en las pinturas rupestres". Coloquios Históricos de Extremadura. Trujillo.

Cartailhac, E. (1906a): "Les mains inscrites en rouges et noires de la grotte de Gargas, comune d'Aventignan". Association Francaise pour l'Avancement des Sciences, Lyon, XXXV, 2: 717-720.

CARTAILHAC, E. (1906b): "Les mains inscrites de rouge ou de noir de Gargas". L'Anthropologie, 17: 624-625.

Clot, A.; Menu, M. y Walter, Ph. (1995): "Manières de peindre des mains à Gargas et Tibiran (Hautes-Pyrénées)". L'Anthropologie, 99: 221-235.

Clottes, J. y Courtin, J. (1994): La Grotte de Cosquer. Peintures et gravures de la caverne engloutie. Edition du Seuil. Ministère de la Culture et du Patrimoine. Paris.

Clottes, J.; Courtin, J.; Valladas, H.; Cachier, H.; MerCIER, N. y ARnOLD, M. (1992): "La Grotte Cosquer datée". Bulletin de la Socièté Préhistorique Française, 89: 230-234.

Delluc, G. y Delluc, B. (1993): "Images de la main dans notre Préhistoire". Monográfico "La Main dans la Préhistoire". Les Dossiers d'Archéologie, 178: 32-45.

GutiérRez Elorza, M. (ed.) (1994): "Introducción a la Geomorfología española”. Geomorfología de España, Editorial Rueda. Madrid: 1-22.

I.G.M.E. (1985): Informe sobre la estabilidad del terreno en el área de "El Calerizo" (Cáceres). Informe no publicado. Instituto Geológico y Minero de España, Ministerio de Industria y Energía, Madrid.

JoRdÁ CERdÁ, F. (1970): "Sobre la edad de las pinturas de la Cueva de Maltravieso (Cáceres)". XI Congreso $\mathrm{Na}$ cional de Arqueología (Mérida, 1968): 139-153. Zaragoza.

Jordá Cerdá, F. y SAnchidrián Torti, J. L. (1992): La Cueva de Maltravieso. Guías Arqueológicas. Mérida.

JoRdÁ PARDo, J.F. (1992): “El profesor D. Eduardo Hernández-Pacheco y su contribución a la Prehistoria española". III Congreso Geológico de España y VIII Congreso Lationoamericano de Geología, Sociedad Geológica de España. Universidad de Salamanca e Instituto Tecnológico y Geominero de España. Salamanca, Simposios, 1: 506-517.

Julivert, M. (coord.) (1983): "Los tiempos precámbricos y paleozoicos. El ciclo hercínico". Libro Jubilar J. M. Ríos. Geología de España. Instituto Geológico y Minero de España, Ministerio de Industria y Energía. Madrid: 57-656.

Julivert, M.; Fontboté, J.M.; Ribeiro, A. y Conde, L. (1972): Mapa Tectónico de la Península Ibérica y Baleares, a escala 1:1.000.000. Instituto Geológico y Minero de España. Madrid.

Leroi Gorhan, A. (1964): Les religions de la Préhistoire (Paléolithique). Presses Universitaires de France (Mythes et Religions). Paris. 
Leroi-Gourhan, A. (1967): "Les mains de Gargas. Essai pour un étude d'ensemble". Bulletin de la Société Préhistorique Française, LXIV, 1: 107-122.

LUQUET, G.H. (1938): "Sur les mutilations digitals". Journal de Psychologie Normale et Pathologique, 35: 548598.

Moure Romanillo, J.A.; González Sainz, C.; Bernaldo de Quirós, F. y Cabrera Valdés, V. (1996): "Dataciones absolutas de pigmentos en cuevas Cantábricas: Altamira, El Castillo, Chimeneas y Las Monedas". “El Hombre Fósil” 80 años después. Santander: 295-324.

Moure Romanillo, J.A. y GonzÁlez Morales, M.R. (1992): "Datation 14C d'une zone décorée de la grotte Fuente del Salin en Espagne". International Newsletter on Rock Art, I.N.O.R.A. Foix, 3: 1-2.

Nougier, L.R. (1984): Premiers éveils de l'homme. Art, Magie, Sexualité dans la Préhistoire. Edit. Lieu Commun. París.

Peyrony, D. (1934): “La Ferrasie”. Préhistoire, 3: 1-92. 89 figuras.

Regnault, F. (1906): "Empreintes de mains humaines dans la grotte de Gargas”. Bulletin et mémoires de la Société d'Anthropologie de Paris: 331-332.

Ripoll LóPEZ, S. y Collado GiRAldo, H. (1996): "Una nueva estación paleolítica en Extremadura. Los grabados de la Cueva de la Mina de Ibor (Castañar de Ibor, Cáceres)". Revista de Estudios Extremeños, LII, 2: 383-399.

Ripoll López, S. y Collado Giraldo, H. (1997): "Nouvelles représentations Paléolithiques en Extremadura la grotte de la Mina de Ibor". International Newsletter on Rock Art, I.N.O.R.A., Foix, 17: 8-11.

Ripoll lópez, S.; Ripoll Perelló, E.; Collado Giraldo, H.; Mas Cornellá, M. y Laboratorio de Estudios Pa-
LEOLíticos (1997): "Avance al estudio de la Cueva de Maltravieso (Cáceres). El arte rupestre paleolítico en Extremadura". Jornadas sobre Arte Rupestre en Extremadura. Extremadura Arqueológica. Cáceres-Mérida, VII: 95-117.

Ripoll Perelló, E. y Moure Romanillo, J.A. (1979): "Grabados rupestres de la Cueva de Maltravieso (Cáceres)". Estudios dedicados a Carlos Callejo Serrano. Cáceres: 567-572.

RodríGuez Vidal, J. y Díaz del Olmo, F. (1994): Macizo Hespérico meridional. Geomorfología de España. Editorial Rueda. Madrid: 101-122.

SAHLY, A. (1966): Les mains mutilées dans l'art préhistorique. Maison Tunisienne de l'édition. Túnez.

SANCHIDRÍAN ToRTI, J. L. (1988/1989): "Perspectiva actual del arte paleolítico de la Cueva de Maltravieso (Cáceres)"'.Ars Praehistorica, Barcelona, VII-VIII: 123-129.

SPINDLER, K. (1993): El hombre de los hielos. El hallazgo que revela los secretos de la edad de piedra. Editorial Galaxia Gutemberg-Circulo de Lectores.

Tena DÁvila, M. y Corretgé, L.G. (1982): Mapa Geológico de España, Escala 1:50.000, Hoja $n^{\circ} 704$ 11-28, Cáceres. Instituto Geológico y Minero de España. Ministerio de Industria y Energía. Madrid.

VAL, J. del y HeRnÁndEZ, M. (1989): "El karst en el Macizo Hespérico". En J. J. Durán y J. López (eds.): El karst en España. Monografías de la Sociedad Española de Geomorfología. Madrid: 217-229.

Valladas, H.; Cachier, H.; Maurice, P.; Bernaldo de Quirós, F.; Clottes, J.; Cabrera Valdés, V.; Uzquiano, P. y ARNold, M. (1992): "Direct radiocarbon dates for prehistoric paintings at the Altamira, El Castillo and Niaux caves". Nature, 357: 68-70. 